\title{
Current Status of Molecular Imaging in Infections
}

\author{
Martina Sollini ${ }^{1}$, Chiara Lauri ${ }^{2}$, Roberto Boni ${ }^{3}$, Elena Lazzeri ${ }^{4}$, Paola Anna Erba ${ }^{4}$ and Alberto Signore ${ }^{2}$
}

${ }^{1}$ Department of Biomedical Sciences, Humanitas University, Pieve Emanuele (Milan), Italy; ${ }^{2}$ Nuclear Medicine Unit, Department of Medical-Surgical Sciences and of Translational Medicine, Faculty of Medicine and Psychology, "Sapienza" University of Rome, Rome, Italy; ${ }^{3}$ Nuclear Medicine Unit, ASST Papa Giovanni XXIII, Bergamo, Italy; ${ }^{4}$ Regional Center of Nuclear Medicine, Department of Translational Research and New Technologies in Medicine, University of Pisa, Pisa, Italy

\begin{abstract}
There is an increased need to find non-invasive tools for early diagnosis and follow-up of infections. Nuclear medicine techniques may be used to diagnose, localize and evaluate the severity and the extent of infections before the occurrence of anatomical abnormalities. This review focuses on different approaches based on radiolabelled cells, peptides and antibodies or $\left[{ }^{18} \mathrm{~F}\right] \mathrm{FDG}$ to image infective diseases in agreement with what is being jointly evaluated by the European Association of Nuclear Medicine (EANM).

This is particularly relevant, since the EANM has strated a wide program of collaboration with other European clinical societies to define common diagnostic flow-charts in many of these infective diseases.

It emerges the role of radiolabelled WBC by SPECT/CT for prosthetic joint infections and of FDG by PET/CT for spondylodiscitis. Comparable values of accuracy have been described for WBC and FDG in the diagnosis of vascular fgraft infections, diabetic gfoot, endocarditis and peripheral bone osteomyelitis, with some exceptions.
\end{abstract}

A R T I C LE H IS T ORY Received: May 1, 2017 Accepted: November 1, 2017

DOI:

$10.2174 / 1381612824666180110103348$

Keywords: Nuclear medicine, radiopharmaceutical, Infection imaging, hybrid imaging.

\section{INTRODUCTION}

In the recent years, we observed an increased need by clinicians to rely on accurate tools for early diagnosis and follow-up of infections, with particular regard to muscoloskeletal and cardiovascular infections. Most importantly, the already available diagnostic techniques need to be correctly positioned in the diagnostic flow-chart of these diseases for a correct management of patients. To this purpose, in the last 10 years the European Association of Nuclear Medicine (EANM), has collaborated with several other European societies (European Society of Radiology, ESR, European Society of Neuroradiology, ESNR, European Society of Cardiology, ESC, European Society) and also with the american Society of Nuclear Medicine and Molecular Imaging (SNMMI).

Several guidelines have been published and others are on the way to be produced. Overall, they emphasize the key role of nuclear medicine techiniques in most occult infections, and most importantly which technique should be peferencially used and when.

Indeed, molecular imaging of infection has been enormously augmented during the past decades, gaining notability in clinical practice for diagnostic and prognostic purposes as well as for treatment decision making. Such strengthening relies on the ability of molecular imaging to point up singular phase of disease onset beside the pure morphological anomalies, generally depicted by the majority of radiological imaging procedures [1].

Computed tomography (CT) and ultrasonography (US) are used for patient's decision making once macroscopic changes are present. However these morphological techniques have some limitations expecially in the early phase of infectious processes when indistinctive sights of disease are manifest and when foreign bodies, implants or prosthesis are present [1].

\footnotetext{
*Address correspondence to this author at the Department of Biomedical Sciences, Humanitas University, via Rita Levi Montalcini I-20090, Pieve Emanuele (Milan), Italy; E-mail: martinasollini@msn.com
}

A large number of radiopharmaceuticals have been developed and used for scintigraphic imaging of infection. Infection specifically refers to the invasion of malignant micro-organisms, whereas inflammation is the response of the immune system against any type of disorder or injury. There may be inflammation without infection or, more rarely, infection without inflammation depending upon the cause of the disease or injury [2].

For infection diagnosis, several radiopharmaceuticals may be used and the choice of the most appropriate mainly depends on pathophysiology and patho-biochemical features of each single disease [2]. In the present scenario, there is no single ideal radiopharmaceutical for imaging infectious diseases. Clinicians must guide their preference according to the purpose of the investigation: when differential diagnosis is the issue, specific radiopharmaceutical should be preferred. In case of low probability of septic disease to define disease extent of a well established diagnosis, less specific molecules may also be considered. Furthermore, distictive propriety to target specifically selected antigen, specific metabolic pathway or cellular process may contribute to therapy decision making and follow-up in different clinical settings. For this scope radiopharmaceutical embracing very high negative predictive value will be preferable. In addition, for the clinically available radiopharmaceuticals that are not targeting the infectious agents, but the immunological response of our body to the infectious noxa, to achieve a differential diagnosis between inflammation and infection specific acquisition parameters and interpretation criteria should be always applied.

Besides the role of well established and novel radiopharmaceuticals, advancements of innovative equipment which have increased spatial resolution allowing the detection of smaller and smaller sites of disease should be also mentioned. Indeed, the event of hybrid imaging, both SPECT/CT and PET/CT has transformed nuclear medicine planar images into 3D functional-anatomical traking of cell function, encouraging the scientific community to a redefinition of their stenght and limitation for a comprehensive patient management. In some clinical condition (i.e. deep structure visualization, post-surgical tissue changes) the use of the CT com- 
ponent of the nuclear medicine procedure is mandatory for the correct interpretation of images. The real challenge of the future will be surely represented by the appropriate definition of the role of multimodal procedures into the complex diagnostic and therapeutic chain allowing the most appropriate and up-to date clinical management.

This review focuses on the current state of the art of nuclear medicine imaging in the most clinically relevant infectious diseases.

\section{MOLECULAR IMAGING OF INFECTION}

\subsection{Bone Infections}

\subsubsection{Peripheral Bone Osteomyelitis}

Osteomyelitis is most commonly caused by pyogenic bacteria and mycobacteria. Hematogenous osteomyelitis is typical of children as consequence of a contiguous focus of infection or associated with vascular insufficiency. Its manifestations are heterogeneous, depending on the age of the patient, specific causative microorganism, anatomic area of involvement, segment of affected bone, route of contamination, systemic and local host factors, as well as the presence of underlying co-morbidities [3-5]. Laboratory tests are generally abnormal in case of acute disease. X-ray is used to exclude other diseases that can mimic osteomyelitis such as fractures and tumors. However, X-ray may take time (10 to 21 days) to identify bone changes since $30 \%$ to $50 \%$ reduction of bone density is necessary to be detectable (sensitivity $43-75 \%$ and specificity $75-$ $83 \%)[3,6]$. MRI is extremely useful for the diagnosis of osteomyelitis and it is the preferred imaging modality when plain radiographs are negative also allowing evaluation of complications (i.e. subperiosteal and soft-tissue abscesses). MRI is highly sensitive for detecting osteomyelitis as early as 3 to 5 days (sensitivity $82-100 \%$ and specificity $75-96 \%$ ). Bone scintigraphy can be performed when symptoms are not localized or there is clinical suspicion for multifocal osteomyelitis [3, 6, 7]. Bone scan is extremely sensitive in diagnosing osteomyelitis $(>90 \%)$ with high specificity in case of underlying normal bone while it decreases to $35 \%$ in case of posttraumatic disease or after surgery. SPECT/CT acquisitions further increase specificity $[6,8]$. Leukocyte scintigraphy presents excellent diagnostic accuracy up to $89 \%$ with value of sensitivity and specificity ranging from $83 \%$ to $89 \%$ and $84 \%$ to $90 \%$ [9-13] (Fig. 1). Accuracy is further improved by the use of time decay corrected protocols for imaging acquisition and by the use of semiquantitative analysis for imaging interpretation $[14,15]$. Similar performances ( $81 \%$ sensitivity and $84 \%$ specificity) were observed for antigranulocyte scintigraphy with MoAbs with higher sensitivity rates observed for peripheral lesions compared with axial lesions [16]. A new murine IgG1k antibody BW 250/183, ${ }^{99 \mathrm{~m}}$ Tc-besilesomab (Scintimun $\left.{ }^{\circledR}\right)$ against granulocytes and granulocyte precursor nonspecific cross-reacting antigen 95 has been more recently introduced for imaging peripheral osteomyelitis. Results of a phase III clinical trial demonstrated that Scintimun ${ }^{\circledR}$ performed similarly to ${ }^{99 \mathrm{~m}} \mathrm{Tc}-\mathrm{HMPAO}-\mathrm{WBC}$, with higher sensitivity $(74.8 \%$ versus $59.0 \%)$ and at slightly lower specificity $(71.8 \%$ versus $79.5 \%$, respectively), particularly in chronic osteomyelitis [17]. However, human anti-murine antibodies (HAMA), detected in $14 \%$ of patients after scintigraphy [17] may limited its application in case of repeated studies. When SPECT/CT is added to planar and tomographic acquisitions, improvement both in diagnosis and localization of infectious site is reported for ${ }^{67} \mathrm{Ga}$ and labeled leukocyte (either ${ }^{111}$ In and ${ }^{99 \mathrm{~m}} \mathrm{Tc}-\mathrm{HMPAO}$ ) in up to $55 \%$ of patients assessed for osteomyelitis [18] or relapsing osteomyelitis on bone with structural abnormalities after trauma $[19,20]$. The main value of hybrid technology is essentially related to the precise anatomic localization of infection and delineation of the extent of the infectious process after the initial identification with planar images [6]. Radiolabeling of leukocyte with $\left[{ }^{18} \mathrm{~F}\right] \mathrm{FDG}$ has been proposed, but data on patients with osteomyelitis are few [21] (accuracy of $46 \%$ according to Rini et al. [9]) and the application still remains experimental. Radiolabeled antibodies performed poorer compared to autologous leukocyte scintigraphy (accuracy ranging from $75-86 \%$ ), while no data on the use of $\left[{ }^{18} \mathrm{~F}\right]$ FDG-PET and PET/CT in primary appendicular osteomyelitis are available (exect for chronic, see below) [10]. ${ }^{99 \mathrm{~m}}$ Tc-ciprofloxacin (Infecton ${ }^{\mathrm{TM}}$, a radiolabeled broad-spectrum fluoroquinolone that inhibits the DNA-gyrase and/or 8 topoisomerase IV of bacteria) have been used in pediatrics patients with clinical suspicion of osteomyelitis (98\% sensitivity and $100 \%$ specificity, with a $100 \%$ positive predictive value and a $87 \%$ negative predictive [22]) despite the low specificity for osteoarticular infections (aspecific accumulation in growth plates, non-infected prosthetic knees, pseudoarthrosis, palindromic rheumatism, and postoperative fibrosis of the lumbar spine, avascular hip necrosis, fibrous dysplasia, non-union fracture, and uninfected prosthetic joints [23-28] (those resultshad also been reported in animal model with another radiolabeled quinolone, ${ }^{14} \mathrm{C}$-sparfloxacin [29]). Preliminary results of ${ }^{68} \mathrm{Ga}$-citrate PET/CT compared to different combinations of diagnostic procedures (MRI, radiography, CT, or labeled WBC scintigraphy), biopsy (when diagnostic), and follow-up data (at least 1 year), have been reported in 31 patients with suspected osteomyelitis or diskitis. ${ }^{68}$ Ga-citrate PET/CT resulted in sensitivity $100 \%$, specificity $76 \%$, positive predictive value $85 \%$, negative predictive value $100 \%$, with an overall accuracy of $90 \%$ ) [30] suggesting its possible role in the diagnosis of bone infections, especially based on its favorable characteristics. Differently from to acute osteomyelitis, low-grade and chronic infections are more difficult to diagnose using current imaging modalities. $\left[{ }^{18} \mathrm{~F}\right] \mathrm{FDG}-$ PET has been reported as the most sensitive and specific technique (88-100\% and $73-95 \%)$ as compared to bone scintigraphy (70-89\% and $16-36 \%)$, leukocyte scintigraphy (43-76\% and $63-87 \%)$ and to combined bone and leukocyte scans (72-100\% and $75-93 \%)$. Sensitivity of WBC scan for chronic osteomyelitis of the peripheral skeleton maintains high value $(72-91 \%)$ while it decreases significantly for the axial skeleton (11-38\%) [10, 31-33]. PET success relies on the ability of $\left[{ }^{18} \mathrm{~F}\right] \mathrm{FDG}$ to be avidly taken up by activated macrophages in the chronic phases of infection. According to the literature, osteomyelitis can be virtually rule out by a negative $\left[{ }^{18}\right.$ F]FDG-PET scan [34-37].

More recently, early dynamic PET/CT using $\left[{ }^{18} \mathrm{~F}\right] \mathrm{NaF}$ or $\left[{ }^{18} \mathrm{~F}\right]$ FDG has been tested in chronic osteomyelitis suggesting that data on the early radiotracer distribution may provide additional information than standard acquisition however results to be validated prospectively in larger trials $[38,39]$.

In case of osteomyelitis of the peripheral skeleton leukocyte scintigraphy (either autologous leukocytes or antigranulocyte MoAbs) presents excellent diagnostic accuracy with important advantage when SPECT/CT is performed. For chronic osteomyelitis of the peripheral skeleton WBC and $\left[{ }^{18} \mathrm{~F}\right]$ FDG-PET perform similarly with a potential advantage in sensitivity of this latter related to the extremely high negative predictive value.

\subsubsection{Sternum, Jaw and Skull Osteomyelitis}

Post-surgery sternal wound infection (both superficial and deep) is a potential life-threatening condition requiring a prompt diagnosis for optimal treatment. The differential diagnosis between superficial and deep infections is crucial since their prognosis is extremely diverse. Superficial infection has a good prognosis when tempestively treated while deep infection presents an unfavourable prognosis [40]. Several radiopharmaceuticals $\left({ }^{67} \mathrm{Ga},{ }^{99 m} \mathrm{Tc}-\mathrm{MDP}\right.$, ${ }^{111}$ In-WBCs, ${ }^{99 \mathrm{~m}} \mathrm{Tc}-\mathrm{HMPAO}-\mathrm{WBC},{ }^{99 \mathrm{~m}} \mathrm{Tc}-\mathrm{MoAb}$ anti-granulocyte antibodies and $\left.\left[{ }^{18} \mathrm{~F}\right] \mathrm{FDG}\right)$ have been used in patients with sternal infections because of limitation of CT findings (low specificity and sensitivity in early phase) and aspirate pitfalls in the immediate post-surgical setting (inflammation), but the real element affecting the diagnostic accuracy of nuclear medicine procedures is the acquisition of tomographic images (included CT co-registration) [41]. Clinically the most extensively used radiopharmaceuticals are ${ }^{67} \mathrm{Ga}$ 

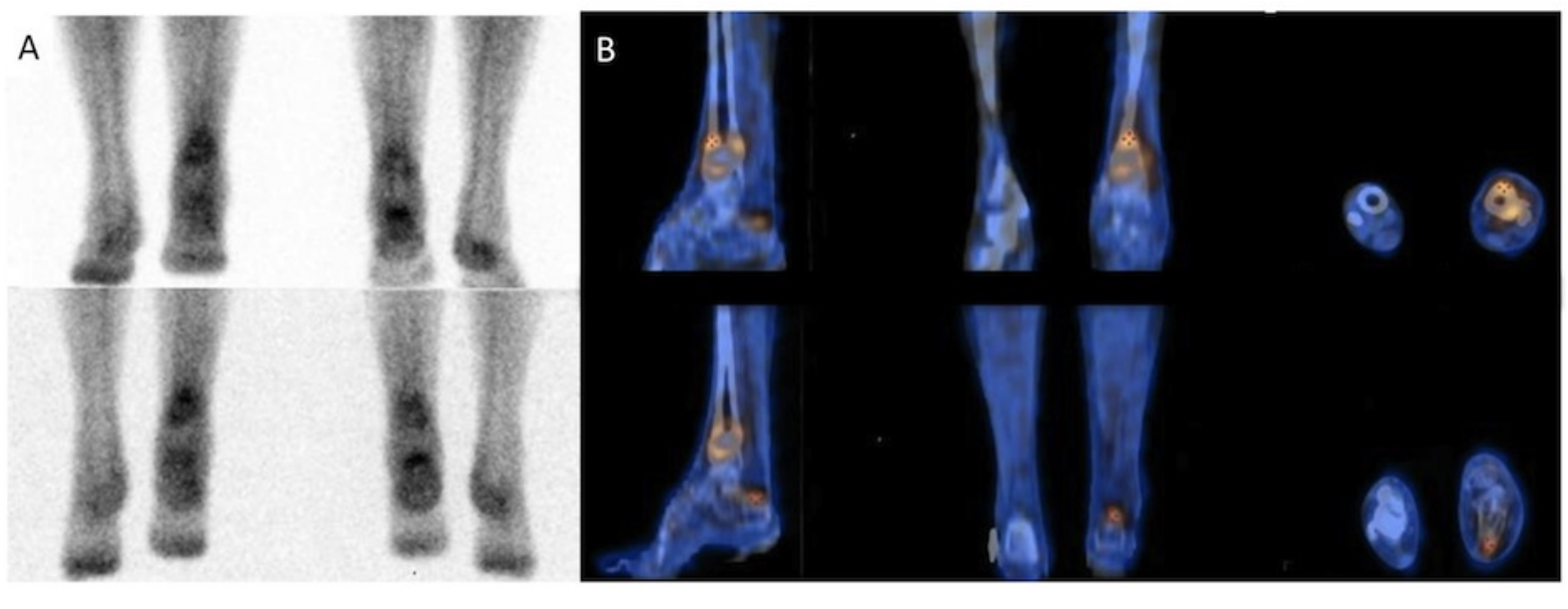

Fig. (1). Post-surgical osteomyelitis in a patient with traumatic fracture of the left tibia. Radiolabelled WBCs planar images at 4 (A upper panel, left anterior view and right posterior view) and $24 \mathrm{hrs}$ (A lower panel, left anterior view and right posterior view) show the presence of a infective foci that at the subsequent SPECT/CT images (B superimposed SPECT/CT images, from left to right sagittal coronal and transaxial images, respectively) was localized at the distal aspect of the tibia and the soft tissue of the calcaneus.

and radiolabeled WBC. Gallium-67 is useless both for high suspicion of sternal bone osteomyelitis and borderline cases (about $74 \%$ sensitivity) $[10,42]$. Labeled WBC scintigraphy has been demonstrated as the most useful technique to differentiate superficial from deep wound infection with higher value of sensitivity, specificity and accuracy (also in the early post-surgical setting) when technetium- $99 \mathrm{~m}$ radiolabeling is used (sensitivity around $100 \%$ and specificity $88 \%$ ) $[10,43,44]$. Additionally, in case of suspicion of mediastinitis relapse a negative labeled WBC scintigraphy is able to rule out infection, potentially impacting on therapeutic management in patients with poor clinical status [45].

Jaw ostemyelitis, either acute or chronic (suppurative, nonsuppurative, osteoradionecrosis bisphosphonate-related, Garre' osteomyelitis, chronic recurrent multifocal, and sclerosing), are uncommon infections often difficult to diagnose resulting in treatment delays and increase morbidity [46-50]. Because pre-therapeutic symptom duration is one of the most significant factors influencing the curability [51] accurate early diagnosis is critical for patients management. Given its frequent odontogenic origin, the initial imaging manifestations of acute osteomyelitis are often observed on plain dental or panorex radiographs. However, X-ray images require a loss of up to $50 \%$ of bone mineral density to reveal disease and these studies may be normal for up to 8 days or even as long as 3 weeks from symptom onset [52]. Three-phase bone scan findings may be abnormal as early as 2 to 3 days after symptom onset [53] and uptake during blood flow phase is not usually observed in chronic forms [54]. However, specificity of the bone scan is poor (79\%) [55]. Recently, the performance of a novel flat-panel SPECT/CT has been evaluated in patients with suspected jaw osteomyelitis in comparison with conventional orthopantomography, planar bone scintigraphy and CT alone [56]. The specificity of planar bone scintigraphy was improved by the use of SPECT/CT acquisition (71\% versus $86 \%$ with an accuracy of $95 \%$ and $98 \%$, respectively) [56]. Additionally SPECT/CT was superior to CT alone $(79 \%)$ and conventional orthopantomography $(66 \%)$ to assess the presence of steomyelitis of the jaw [56]. Specificity of radionuclide examinations is better (especially in patients with indwelling surgical hardware) when using radiolabeled WBC [44] (around 100\% sensitivity, $67 \%$ specificity, $62 \%$ positive predictive value, and $100 \%$ negative predictive value) [55]. In treatment-responsive disease, abnormal uptake on WBC scans resolves earlier than CT abnormalities. Additionally, in patients who have contraindications for MRI or those with surgical hardware artifacts that adversely affect MRI quality, WBC scintigraphy is an excellent alternative for treatment surveillance. Whole-body imaging is also useful for de- tection of multiple sites of disease involvement in cases of nonsuppurative primary chronic mandibular osteomyelitis associated with systemic diseases or chronic recurrent multifocal osteomyelitis. If surgical treatment is planned, high-resolution CT is required to specify the degree of cortical destruction, the presence of sequestra in particular, and to define the extent of osseous removal required [49]. Comparative studies of the various modalities are not currently available.

Infections of the skull both primary and post-surgical are generally diagnosed by neurologic examination, laboratory tests and radiological imaging (CT and MRI); however in particular case additional tests are required. Osteomyelitis of the skull is a typical case of improved detection by means of SPECT and SPECT/CT acquisition [57-59]. Nevertheless, few clinical data are available and radiolabeled dyphosphonates and $\left[{ }^{18} \mathrm{~F}\right] \mathrm{FDG}$ the most commonly used radiopharmaceutical, primarily for otogenic cranial base [60] and chronic osteomyelitis [61, 62].

\subsubsection{Spondylodiscitis}

Spine infection (also defined as spondylodiscitis, SD) can be primary (haematogenous) or secondary (prevalently due to spine surgery). An early diagnosis is mandatory to establish a proper therapy that when delayed can result in irreversible neurological impairment [63]. The clinical suspicious of spine infection must be confirmed or ruled out by diagnostic imaging, including radiological and nuclear medicine procedures $[64,65]$. MRI is the technique of choice in patients with suspected spinal infection especially in haematogenous SD [63]. Nevertheless, post-surgical structural changes may hamper correct interpretation of MRI, thus its diagnostic role during patients follow-up and disease monitoring is questioned [63, 66-69]. CT-guided biopsy has high specificity $(100 \%)$ but it not routinely employed since its sensitivity ranges between $58 \%$ and $91 \%$ [70, 71]. Bone and Gallium-67 scans performed similarly (sensitivity of $81 \%$ and $41 \%$, specificity of $86 \%$ and $36 \%$, respectively). Radiolabeled WBC scintigraphy sensitivity and specificity have been reported ranging from $63 \%$ to $84 \%$ and from $55 \%$ to $100 \%[10,14]$. SD appears as a "cold" spot at WBC scan (Fig. 2). $\left[{ }^{18} \mathrm{~F}\right]$ FDG-PET is considered the most sensitive technique for spine infection diagnosis (about 100\%), but lower specificity $(88 \%)$ is the main the limitation of the technique $[10,35]$. False positive findings are possible in case of degenerative lesions, bone tumours and post-surgical changes [72]. More recently Fuster et al. [73] proposed a pattern of $\left[{ }^{18} \mathrm{~F}\right] \mathrm{FDG}$ uptake to increase $\mathrm{PET} / \mathrm{CT}$ accuracy. Accordingly to this visual criterion, PET/CT was considered positive when $\left[{ }^{18} \mathrm{~F}\right] \mathrm{FDG}$ uptake was higher than bone 

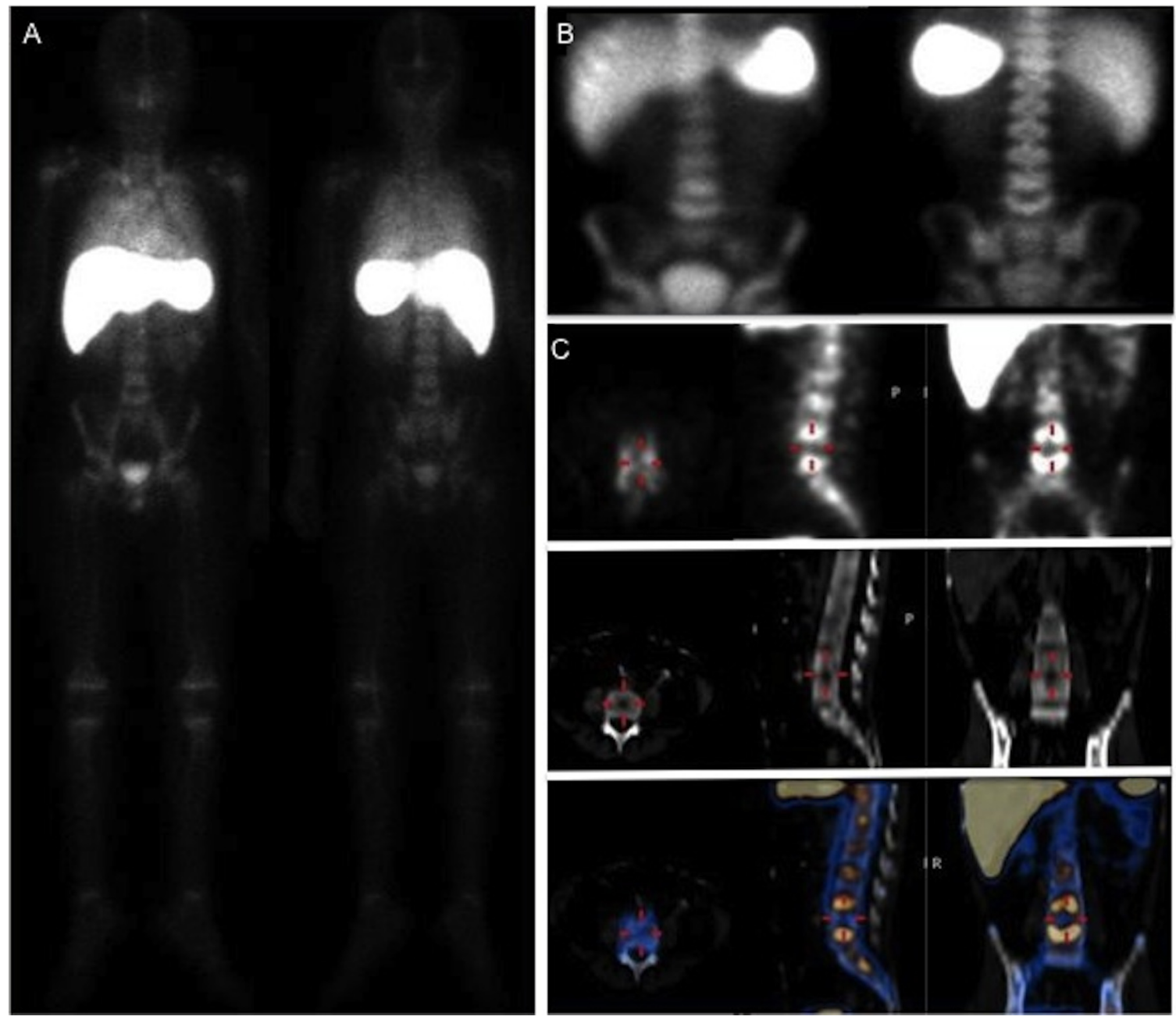

Fig. (2). Radiolabeled WBC scintigraphy in a patient with haematogenous spine infection. Whole-body images 30 minutesa after the radiopharmaceuticals administration (A, at left anterior and at right posterio), planar spot images of the admonel-upper pelvis (B, anterior at left and posteriori at right) and SPECT/CT images (C, upper panel emission, middle panel CT and lower panel superimposed SPECT/CT from left to right transaxial, sagittal and coronal and images, respectively) show a "cold" spot in the lumbar spine at the level of L4-L5.

marrow uptake in adjacent vertebras and/or in presence of soft tissue uptake [73]. Additionally, $\mathrm{SUV}_{\max }$ in an area surrounding the lesion suspected of infection and the background $\mathrm{SUV}_{\text {mean }}$ in a preserved area of the spine were calculated in all patients. In this series of patients, $\left[{ }^{18} \mathrm{~F}\right] \mathrm{FDG}$ uptake (quantified as $\mathrm{SUV}_{\max }$ ) was significantly higher in patients with spondylodiscitis $(p<0.005)$ using an estimated threshold of 5.324 (95\% CI $4.465-6.183)$. The use of $\mathrm{SUV}_{\max }$ corrected by the background $\mathrm{SUV}_{\text {mean }}$ led to a higher level of significance than the use of $\operatorname{SUV}_{\max }$ alone $(p<0.001)$ with an estimated threshold of 2.2 (95\% CI 2.113 - 2.287). The use of $\mathrm{SUV}_{\max }$ and $\mathrm{SUV}_{\max }$ corrected by the background $\mathrm{SUV}_{\text {mean }}$ showed sensitivities of $56 \%$ and $89 \%$, respectively, with $100 \%$ specificity for both [73]. Using $\left[{ }^{18} \mathrm{~F}\right] \mathrm{FDG}-\mathrm{PET} / \mathrm{CT}$ a strong impact on patients clinical management due to the guidance of the most suitable therapeutic strategy (i.e. start antibiotic therapy or surgical intervention) has been demonstrated in up to $52 \%$ of cases $[74,75]$. The use of semi-quantitative parameters (e.g. $\mathrm{SUV}_{\max }$ ) may be useful to discriminate infection of the spine from other processes $[73,75]$. The high negative predictive value of $\left[{ }^{18} \mathrm{~F}\right] \mathrm{FDG}-\mathrm{PET} / \mathrm{CT}$ make it a useful method for the discrimination of residual and non residual spine infection during and after treatment (i.e. with use of quantitative indexes \% deltaSUVmax) [76-80]. Fig. 3 shows an example of $\mathrm{PET} / \mathrm{CT}$ in a patient with haematogenous spine infection by MRSA.
Preliminary results with ${ }^{99 \mathrm{~m}} \mathrm{Tc}$-ubiquicidin $29-41$ have been reported in patients with suspected SD. The sensitivity and specificity for detecting SD were $100 \%$ and $87 \%$, respectively with a positive predictive value of $95 \%$ and a negative predictive value of $100 \%$. Although this method was useful in this group of patients to reach at a certain diagnosis, the role of this method in the diagnostic protocol of the patient with suspected SD has not yet been defined [81]. The use of ${ }^{99 \mathrm{~m}} \mathrm{Tc}$-ciprofloxacin has been extended to axial skeleton infections without conclusive results: high sensitivity $(100 \%)$ with a maximum specificity of $74 \%$ when SPECT is acquired, but with high false positive rate particularly in the early post-operative setting [35]. An infection specific radiopharmaceutical, ${ }^{111}$ In-Biotin has been extensively studied in patients with spine infection showing $(n=180)$ high accuracy $(92-93 \%)$ [63, 82]. However, this radiopharmaceutical is still in-home experimental preparation and it is not yet commercially available.

In conclusion $\left[{ }^{18} \mathrm{~F}\right] \mathrm{FDG}-\mathrm{PET} / \mathrm{CT}$ should be considered the first choice radionuclide test in the presence of high suspicious of spine infection and potentially for the follow-up of patients after antibiotic treatment. The pattern of uptake should be used to increase the diagnostic accuracy. However, it fails in differential diagnosis between infection and others bone pathologies (i.e. spine metastasis, osteoarthritis), thus making an infection specific radiopharmaceutical the really warrant. 

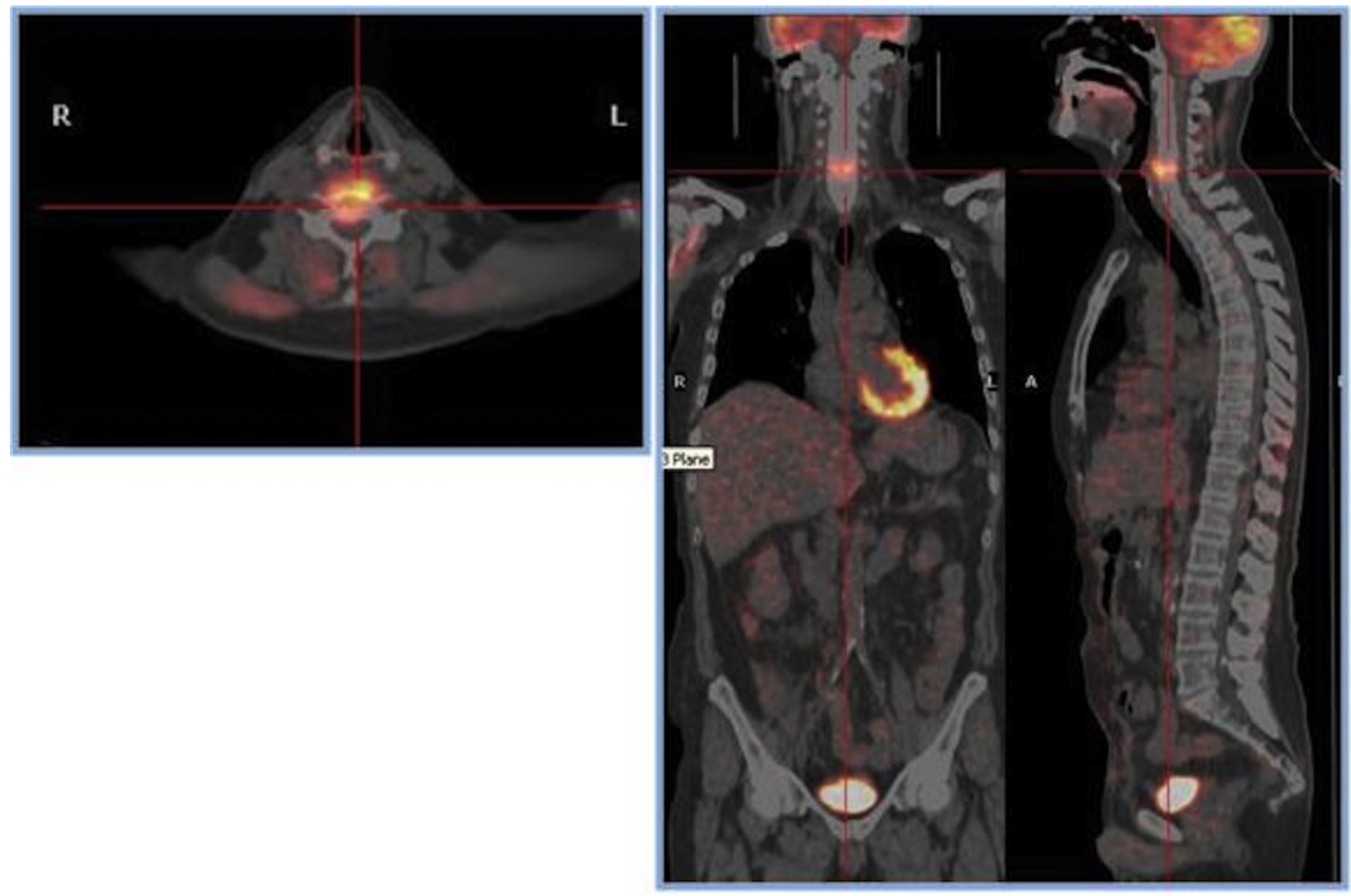

Fig. (3). $\left[{ }^{18} \mathrm{~F}\right] \mathrm{FDG}$ PET/CT in a patient with suspected haematogenous spine infection by MRSA. Fused transaxial (left panel), coronal (middle panel) and sagittal (right panel) PET/CT images show an area of increased radiopharmaceutical uptake at the cervical spine. Linear pattern of uptake at C5-C6 consistents with the clinical suspicious of spine infection.

\subsubsection{Diabetic Foot Infection}

Osteomyelitis of the foot is one of the most commonly encountered complications in diabetic patients. Early diagnosis of diabetic foot infection is crucial to define the treatment [6]. Three-phase bone scintigraphy demonstrated extremely high sensitivity even in the absence of signs and symptoms (69-100\%) [6]. Nevertheless, fracture, the neuropathic joint, and even the pedal ulcer all can yield positive 3-phase bone scans making the specificity of the method relatively low (28-62\% with lower value of $10 \%$ in only one series) [83-92]. To improve sensitivity different attempts have been made. The acquisition of 24 hours image (4-phase) was able to increase specificity $(87 \%$ versus $73 \%)$ with a lack in sensitivity $(80 \%$ versus $100 \%$ ) and $85 \%$ accuracy adding to semiquantitative analysis [93, 94]. Evaluation of perfusion at 3-phase bone scan in site of suspected infection (arterial hyperperfusion associated with ostepmyelitis venous hyperperfusion with soft tissue infection) allowed to obtain $94 \%$ sensitivity and $79 \%$ specificity [95].

Sensitivity and specificity values of radiolabeled WBC in the diagnosis of diabetic foot infection ranging from $75 \%$ to $100 \%$ and from $69 \%$ to $89 \%[83,87,96]$ for ${ }^{111}$ In-oxine labeling while for ${ }^{99 \mathrm{~m}} \mathrm{Tc}$-HMPAO labeling range from $86 \%$ to $93 \%$ and $80 \%$ to $98 \%$ [88, 89, 97].

Compared to bone scan, leukocyte imaging demonstrates higher sensitivity (89\% versus $69 \%$ ) and specificity (69\% versus $39 \%)$ $[86,98]$. All studies are based on the evaluation of planar early and delayed images (4 and 24 hours) with some specific interpretation criteria (i.e. radiotracer uptake increased from early to late images). Using bone scan as anatomic reference, sensitivity and specificity may be improved (up to $100 \%$ and to $97 \%$, respectively) $[89,96]$. SPECT/CT may contribute to increase the specificity of the labeled leukocytes imaging substituting CT acquisition to the injection of ${ }^{99 \mathrm{~m}} \mathrm{Tc}-\mathrm{MDP}$; the ability to discriminate bone involvement from the sole soft tissue localization of infection results in a modification of the interpretation of images in up to $53 \%$ of cases both with Gallium-67 and radiolabeled WBC [18, 99]. Despite proved utility, the small size of metatarsal and foot toes may hamper difficulties in the evaluation and discrimination of bone form soft tissue even with SPECT/CT; probably the use of new generation SPECT/CT equipment with multislices CT detector might overcome these obstacles. Additionally, radiolabeled WBC SPECT/CT showed higher specificity and positive predictive value than three-phase bone scintigraphy in predicting osteomyelitis relapse after antibiotic treatment discontinuation (91\% versus $12 \%$ and $71 \%$ versus $15 \%$, respectively) [100]. Dual-isotope SPECT/CT $\left({ }^{99 \mathrm{~m}} \mathrm{Tc}-\mathrm{HMDP}\right.$ plus ${ }^{111} \mathrm{In}-$ WBC) has been compared to conventional imaging (plain radiography, CT, planar bone scan, planar ${ }^{111}$ In-WBC scan, and MRI) in a similar number of patients (227 versus 232). In this large population of diabetic patients with suspected foot infection, dualisotope SPECT/CT was more accurate in diagnosing and localizing infection compared with conventional imaging. Nonetheless, it provided clear guidance, promoted many limb salvage procedures, and was associated with considerably reduced length of hospitalization compared with conventional imaging impacting also on health economics [101].

Combined 4-phase MDP and ${ }^{99 \mathrm{~m}} \mathrm{Tc}-\mathrm{HMPAO}-\mathrm{WBC}$ resulted in higher sensitivity and specificity ( $91 \%$ and $67 \%$ ) compared to MRI (78\% and 60\%) and microbiological examination (92\% and $60 \%)$ using histopathologic bone tissue specimens as gold standard [102]. More recently, MRI has been fused with ${ }^{111} \mathrm{In}-\mathrm{WBC} / /^{99 \mathrm{~m}} \mathrm{Tc}-\mathrm{HDP}$ SPECT/CT in a small series of diabetic foot infections patients in order to better localize the infection helping in conservative treatment planning and limbing salvage procedures [103].

Radiolabeled anti-granulocytes antibodies have demonstrated value of sensitivity and specificity of about $93 \%$ and $78 \%$ for MAb 
BW 250/183 [104], 90\% and 67\% for murine IgM mAb (against CD15, Fanolesomab) [90] and $95 \%$ and $70 \%$ for an antigranulocyte antibody murine IgG anti-NCA-90 (Leukoscan ${ }^{\circledR}$ ) [105].

The combination of Leukoscan and ${ }^{99 \mathrm{~m}} \mathrm{Tc}-\mathrm{MDP}$ bone scan shows better sensitivity and specificity when compared to bone and ${ }^{67} \mathrm{Ga}$ scan combination $(67-86 \%$ and $84-85 \%$ versus $44 \%$ and $77 \%$, respectively) [106, 107]. As compared to ${ }^{99 \mathrm{~m}} \mathrm{Tc}-\mathrm{MDP} 3$-phase scintigraphy performances ${ }^{99 \mathrm{~m}} \mathrm{Tc}-\mathrm{IgG}$ demonstrated similar sensitivity with higher specificity ( $63 \%$ versus $54 \%$ ) and accuracy $(83 \%$ versus $74 \%$ ). Specificity may be improved by 24 hours images evaluation $(77 \%)$ at the price of decrease of overall accuracy (70\%) [108]. Infecton ${ }^{\mathrm{TM}}$ has also been evaluated in diabetic foot osteomyelitis, mainly in association with 3-phase bone scintigraphy (accuracy around $72 \%$ ); false negative results generally occours in case of ciprofloxacin-resistant bacterial flora $[25,109-111] .{ }^{99 \mathrm{~m}}$ Tc-labelled nanocolloids scintigraphy has also been used in a limited series of diabetic patients with neuropathic foot disease showing high sensitivity $(100 \%)$ and low specificity (about $60 \%$ ) mainly as a consequence of the aspecific mechanism of accumulation in infectious site (extravasation through the capillary basement membrane, followed by phagocytosis or adsorption of the particles by granulocytes and macrophages) [112].

Aslangul et al. [113] evaluated a method for definitively diagnosing osteomyelitis in patients presenting with a foot ulcer and clinically suspected osteomyelitis but without soft tissue infection. They used a combined approach using ${ }^{67} \mathrm{Ga}$-SPECT/CT plus a percutaneous bone puncture. In case of postive scan and positive bone culture patients recieved culture-guided antimicrobial treatment while patients with negative imaging or with positive imaging but negative bone culture were not treated. This approach resulted in high sensitivity and specificity (88\% and 94\%) for diagnosing diabetic foot osteomyelitis, obviating the need for antibiotic treatment in more than half of suspected cases.

More recently, the utility of ${ }^{99 \mathrm{~m}} \mathrm{Tc}$-ubiquicidin $29-41$ scintigraphy in combination with three-phase bone scan, has been evaluate in a pilot study in 65 diabetic patients with suspected osteomyelitis of the foot with very promising results (sensitivity, specificity and accuracy of $100 \%)$ [114].

$\left[{ }^{18} \mathrm{~F}\right]$ FDG-PET and PET/CT represent an extremely interesting possibility for the evaluation of diabetic foot complications. Initial data on the use of $\left[{ }^{18} \mathrm{~F}\right] \mathrm{FDG}-\mathrm{PET} / \mathrm{CT}$ in diabetic foot infection, demonstrate increased $\left[{ }^{18} \mathrm{~F}\right] \mathrm{FDG}$ with the possibility to differentiate soft tissue from bone uptake by $\mathrm{CT}$ imaging with overall accuracy of $70-90 \%$ with $\left[{ }^{18} \mathrm{~F}\right]$ FDG-PET $[115,116]$, increasing up to $95 \%$ with $\left[{ }^{18}\right.$ F]FDG-PET/CT [117-119]. Few and contractictory data are available on the comparison between $\left[{ }^{18} \mathrm{~F}\right] \mathrm{FDG}-\mathrm{PET}$ and MRI since first experience describing MRI as most accurate than PET $(90 \%$ versus 70\%) [115] have been confuted (MRI 81\% versus PET 90\%) [116].

A direct comparison between three-phase bone scan and $\left[{ }^{18} \mathrm{~F}\right]$ FDG-PET/CT in 79 patients with complicated diabetic foot, showed higher specificity and NPV for $\left[{ }^{18} \mathrm{~F}\right]$ FDG-PET/CT than three-phase bone scan in diagnosing pedal osteomyelitis $(71 \%$ versus $28 \%$ and $71 \%$ versus $40 \%$ ) while three-phase bone scan was found to be more sensitive and useful than $\left[{ }^{18} \mathrm{~F}\right] \mathrm{FDG}-\mathrm{PET} / \mathrm{CT}$ in detecting early Charcot's neuropathy as it incrementally diagnosed early neuropathic foot in 8 more patients thereby warning the clinician to bring about more stricter glycemic controls in them and to adopt preventive conservative measures like off-loading of the foot or advising molded foot wear in them so as to help prevent further clinical or symptomatic deterioration [92].

A direct comparison between $\left[{ }^{18} \mathrm{~F}\right] \mathrm{FDG}-\mathrm{PET}$ and ${ }^{99 \mathrm{~m}} \mathrm{Tc}$-labeled monoclonal anti-granulocyte antibody scintigraphy in diabetic patients with chronic foot ulcers, showed a clear advantage of $\left[{ }^{18} \mathrm{~F}\right]$ FDG-PET $(70 \%$ versus $65 \%$ accuracy) with high negative predictive value. Furthermore, $\left[{ }^{18}\right.$ F]FDG-PET may be used for differentiating osteomyelitis and soft tissue infection from the uncomplicated neuropathic joint (accuracy of about $94 \%$ versus $75 \%$ of MRI) [117].

A direct comparison between $\left[{ }^{18} \mathrm{~F}\right] \mathrm{FDG}-\mathrm{PET} / \mathrm{CT}$ (three time points images at 10 minutes, 1 and 2 hours after radiopharmaceutical administration) and ${ }^{99 \mathrm{~m}} \mathrm{Tc}-\mathrm{HMPAO}-\mathrm{WBC}$ scintigraphy (early and delayed images) has also been performed in diabetic patients with pedal osteomyelitis [120]. Using a time dependent increased target/background ratio $>2.0$ at 20 hours images as interpretation criteria for a positive scan ${ }^{99 \mathrm{~m}} \mathrm{Tc}-\mathrm{HMPAO}-\mathrm{WBC}$ scintigraphy, sensitivity, specificity, positive predictive value, negative predictive value, and accuracy for osteomyelitis diagnosis were $86 \%, 100 \%$, $100 \%, 86 \%$, and $92 \%$, respectively. Similarly, for $\left[{ }^{18}\right.$ F $]$ FDG-PET the better interpretation criteria for the diagnosis of osteomyelitis was a SUVmax value $>2.0$ at 2 hours scan with time-increasing fashion (sensitivity $=43 \%$, specificity $=67 \%$, positive predictive value $=60 \%$, negative predictive value $=50 \%$, and accuracy $=$ $54 \%$ ); combining visual assessment of PET images at 1 hours and CT findings the diagnostic accuracy increased to $62 \%$.

In conclusion, radiolabeled leukocyte imaging is the nuclear medicine procedure of choice for investigation of diabetic foot infections. In presence of low clinical suspicion of osteomyelitis of the forefoot and contemplated medical treatment, a 3-phase bone scan followed by a radiolabeled leukocytes scintigraphy are the studies of choice. For suspected infection of the mid and hind foot, radiolabeled leukocytes imaging is the most accurate test for determining the presence of infection, although, a positive result may requires a complementary study with a marrow agent. SPECT/CT acquisition will improve diagnostic accuracy, especially in the mid and hind foot while for the evaluation of the forefoot it may be useless. Data on $\left[{ }^{18}\right.$ F]FDG-PET and PET/CT are limited, but extremely promising and require further investigation before the introduction into daily clinical practice.

\subsubsection{Prosthetic Joint Infections}

While radiographic technique may be easily diagnosed prosthesis failures caused by heterotopic ossification, fracture, and dislocation differential diagnosis between aseptic loosening ( $>25 \%$ of all prostheses and associated with inflammation with histiocytes, giant cells, lymphocytes and plasma cells recruitment and generally managed with a single-stage exchange arthroplasty) and infection (about $1-2 \%$ for primary implants, $3-5 \%$ for revision implants characterized by neutrophils infiltrations, treated with debridement without removal of the prosthesis, one or two-stage replacement + protracted antimicrobial therapy, permanent removal + arthrodesis + suppressive long term antibiotic treatment) is challenging. Clinical signs, biochemical tests may be absent and inconclusive. Joint aspiration with Gram stain and culture (considered the gold standard) presents variable sensitivity ranging from $28 \%$ to $92 \%$ (specificity $92-100 \%$ ). Plain radiographs are neither sensitive nor specific and CT and MRI may be limited by hardware induced artifacts. Functional procedures already considered the method of choice for such differential diagnosis, but suffering from the limitation of poor anatomical landmarks, have increased diagnostic accuracy with the availability of hybrid imaging modalities (SPECT/CT and PET/CT, Fig. 4). The most extensively used radiopharmaceutical for bone infection diagnosis is represented by radiolabeled autologous leukocytes (either with ${ }^{99 \mathrm{~m}} \mathrm{Tc}-\mathrm{HMPAO}$ or ${ }^{111}$ In-Oxina associated with bone marrow images) with about, $89 \%$ diagnostic accuracy, sensitivity $(83-89 \%)$ and specificity $(84-94 \%)[9,10]$. The use of standardized acquisition protocol using time-decay corrected images $[14,15]$ as well as SPECT/TC acquisition further increase the diagnostic accuracy by either decreasing the rate of false positive findings and allowing more accurate anatomical localization and extension of bone and joint infection site [14, 15,19, 121, 122].

$\left[{ }^{18} \mathrm{~F}\right] \mathrm{FDG}$ in vitro radiolabeled leukocytes represent an initial attempt to develop an infection-specific, positron-emitting tracer 

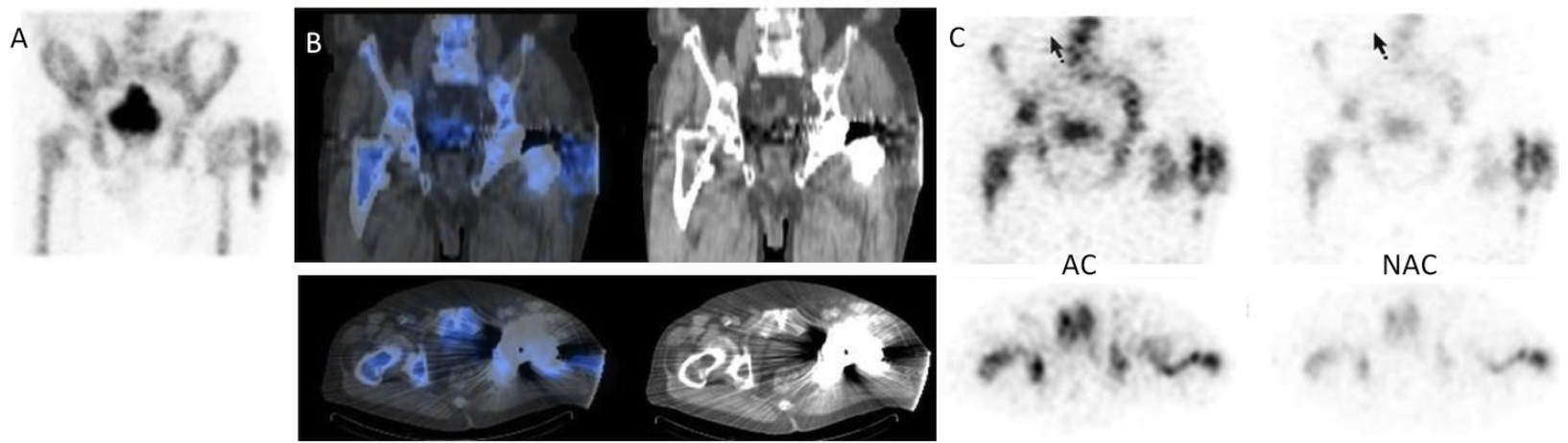

Fig. (4). Radiolabeled WBC scintigraphy in a patient with left hip prosthesis infection. MIP imges (A) and SPECT/CT images (B, upper panel coronal and lower panel transaxial, from left to right superimposed SPECT/CT, CT, emission AC and emission NAC) diagnosed the presence of prosthetic infection complicate with a fistula in the soft tissue.

$[123,124]$. In patients with infected prosthesis first results (in conjunction to marrow imaging) demonstrated similar diagnostic accuracy to ${ }^{111}$ In-WBC [8] but with significant low labeling efficiency when $\left[{ }^{18} \mathrm{~F}\right] \mathrm{FDG}$ is used.

${ }^{99 \mathrm{~m}} \mathrm{Tc}$-radiolabeled murine anti-granulocyte $\mathrm{mAb}$ showed a sensitivity ranging from $75-91 \%$ and specificity of $81-86 \%$ with a negative predictive value of $66-96 \%[10,16,125,126]$. Increase in specificity (from $71 \%$ to $83 \%$ and from $78 \%$ to $100 \%$ ) without significant changes in sensitivity $(94 \%$ and $93 \%$ ) has been demonstrated in hip and knee prosthesis with dual-time acquisition protocol (4 and 20-24 hours images) [127, 128]. Quantitative evaluation of sulesomab (activity in ROI around the knee prosthesis and the pelvic bone marrow with $10 \%$ threshold to differentiate between septic and aseptic abnormalities) increased significantly both sensitivity and specificity compared to visual interpretation, particularly in moderate-low grade infection [129]. A comparative study using ${ }^{99 \mathrm{~m}} \mathrm{Tc}$-besilesomab and ${ }^{99 \mathrm{~m}} \mathrm{Tc}$-sulesomab showed similar diagnostic accuracy for the detection of septic total knee arthroplasty [130]. Additionally, ${ }^{99 \mathrm{~m}} \mathrm{Tc}$-sulesomab scintigraphy combined with ${ }^{99 \mathrm{~m}} \mathrm{Tc}$ nanocolloid bone marrow scan have demonstrated to improved both specificity and positive predictive value [131].

Attempts to increase scintigraphic specificity, investigation of a number of other radiopharmaceuticals is ongoing. ${ }^{99} \mathrm{Tc}-$ ciprofloxacin at 24 hours images has demonstrated better performances for the diagnosis of knee prosthesis infection in a small series of patients (sensitivity and specificity of $83 \%$ and $90 \%$, respectively) as compared to hip prosthesis (sensitivity of $74 \%$ and specificity of 90\%) [132]. Similarly, based on results in several animal models where radiolabeled Annexin V, a marker of apoptosis and cellular stress or activation, have demonstrated ability to detected acute, subacute, and chronic inflammation, this radiopharmaceutical was tested in patients, suggesting a potential application in the differentiation of infection (uptake more common and intense) from aseptic loosening [133].

PET using either $\left[{ }^{18} \mathrm{~F}\right]$-fluoride and $\left[{ }^{18} \mathrm{~F}\right] \mathrm{FDG}$ has been proposed as alternative imaging modality to leukocyte scintigraphy during the last years. $\left[{ }^{18} \mathrm{~F}\right]$-fluoride has been used to guide tissue sampling to confirm infection of hip prosthesis (sensitivity of the combined histopathology, microbiological culture, real-time PCR of $96 \%$ when sampling only major $\left[{ }^{18} \mathrm{~F}\right]$-fluoride uptake sites) [134]. Results for $\left[{ }^{18}\right.$ F]FDG-PET have demonstrated about 73-95\% accuracy for bone prosthesis infection diagnosis with $81-95 \%$ of sensitivity, and specificity of $66-95 \%$ considering both periprosthetic or bone-prosthesis interface $\left[{ }^{18} \mathrm{~F}\right] \mathrm{FDG}$ uptake as interpretation criteria [10, 135-140]. Many interpretative criteria have been introduce to improve diagnostic performances of $\left.{ }^{18} \mathrm{~F}\right] \mathrm{FDG}-\mathrm{PET}$ and PET/CT in prosthetic joint infections. Stumpe et al. [141] dif- ferentiated aseptic loosening from infection deemed positive for infection only cases presenting similar or higher $\left[{ }^{18} \mathrm{~F}\right] \mathrm{FDG}$ uptake than bladder (grade 3 or 4 ) according to a 5-point scale (accuracy $=69 \%$ ). Reinartz et al. [142] based their evaluation on $\left.{ }^{18} \mathrm{~F}\right]$ FDG pattern of uptake considering suggestive for hip prosthesis infection only cases presenting periprosthetic involvement (sensitivity $=94 \%$, specificity $=95 \%$, accuracy $=95 \%$ ). Chacko et al. [143] considered positive for infection increased $\left[{ }^{18} \mathrm{~F}\right] \mathrm{FDG}$ uptake at the prosthesis-bone interface (sensitivity $=92 \%$, specificity $=97 \%$ ) while for Wenter et al. [135] a higher bone $\left[{ }^{18} \mathrm{~F}\right] \mathrm{FDG}$ uptake compared to adipose tissue or inactive muscles (considered as background) was considered positive for infection. Love et al. [144] proposed and compared different criterion to evaluate prosthesis infection. According to the first one the presence of any $\left[{ }^{18} \mathrm{~F}\right] \mathrm{FDG}$ uptake adjacent to the prosthesis (prosthesis-bone interface, tip of prosthesis and/or soft tissues surrounding prosthesis) was indicative for infection (sensitivity $=100 \%$, specificity $=9 \%$, accuracy $=47 \%$ ); the second one was the same proposed by Chacko et al. [143] (sensitivity $=96 \%$, specificity $=35 \%$, accuracy $=61 \%$ ); the third one took into account the prosthesis-bone interface activity, regardless of intensity (sensitivity $=52 \%$, specificity $=44 \%$, accuracy $=47 \%$ ), and the fourth criterion used a semi-quantitative analysis calculating a target-to-background ratio between the most intense activity at the bone interface and the uptake of the soft tissue of the corresponding controlateral side (sensitivity $=36 \%, \quad$ specificity $=97 \%$, accuracy $=71 \%$ ) [144].

Wenter et al. [135] compared their method to others in patients with orthopaedic implant confirming a very high sensitivity for the criterion 1 suggested by Love et al. $(100 \%)$ compared to others (Familiari $=83 \%$, Stumpe $=84 \%$, Reinartz $=87 \%$, Chacko $=77 \%$, Love criterion $4=61 \%$, and their ones $=86 \%$ ) despite the highest specificity and accuracy were reached using the method proposed by themselves $(67 \%$ and $76 \%$, respectively) compared to other (Familiari $=54 \%$ and $=68 \%$, Stumpe $=37 \%$ and $=61 \%$, Reinarzt $=29 \%$ and $=56 \%$, Chacko $=46 \%$ and $=61 \%$, Love criterion $1=20 \%$ and $=58 \%$, Love criterion $4=63 \%$ and $=62 \%$ ).

Specificity of the technique may be improved used PET/CT evaluation of both NAC images and $\mathrm{AC}$ as demonstrated in patients with painful primary hip prostheses (from $62 \%$ to $87 \%$ ) and in patients with an interim hip spacer (from 50\% to 62\%) [145]. Despite encouraging results, clinical comparative study have demonstrated that leukocyte/bone [31] as well leukocyte/marrow imaging are more accurate than $\left[{ }^{18} \mathrm{~F}\right] \mathrm{FDG}-\mathrm{PET}$ and PET/CT (any interpretation criteria: any periprosthetic activity, regardless of location or intensity; periprosthetic activity, without corresponding activity on the marrow image; only bone-prosthesis interface activity, regardless of intensity; semiquantitative analysis-a lesion-to-background ratio) 
for differential diagnosis between aseptic and septic loosening [144, 146]. Nevertheless better performances of $\left[{ }^{18}\right.$ F]FDG-PET compared to ${ }^{111}$ In-oxina leukocytes/marrow imaging for the diagnosis of periprosthetic infection of the hip has also been reported $(95 \%$ and $93 \%$ versus $50 \%$ and $95 \%$ ) [137]. The main argument in the use of $\left[{ }^{18} \mathrm{~F}\right] \mathrm{FDG}$ for the differential diagnosis of prosthesis infection is due to the finding of increased $\left[{ }^{18} \mathrm{~F}\right] \mathrm{FDG}$ uptake in case of inflammatory arthritis, fractures, normally healing bone, degenerative changes [147, 148], synovial proliferation [149], muscle activity due to malalignment of knee replacement and soft tissue imbalance, heterotopic ossification, granuloma and neuroma [150]. However, in contrast to ${ }^{99 \mathrm{~m}} \mathrm{Tc}$-diposfonates, $\left[{ }^{18} \mathrm{~F}\right] \mathrm{FDG}$ rapidly normalizes after traumatic or surgical fractures $[151,152]$ as consequence of fibroblasts predomination in normally healing bone, subsiding 4 months after surgery [153]. Therefore, specificity increases if recently (less than 4 months) traumatized or operated bone is excluded and if when all possible sources of false positive findings are ruled out.

The monitoring of antimicrobial treatment response in patients with infected joint prosthesis by nuclear medicine procedure is currently clinically applied, despite validated clinical trials supporting this use of PET and scintigraphy are still lacking. In fact, few data are available to support such use of either radiolabeled leukocytes and $\left[{ }^{18} \mathrm{~F}\right] \mathrm{FDG}$ in this clinical setting. The combination of gallium-67 and technetium-99m MDP using as positivity criteria gallium uptake $>{ }^{99 \mathrm{~m}} \mathrm{Tc}$ MDP have demonstrated the ability of nonarbitrary determine the moment of reimplantation of the prosthesis (no clear consensus regarding the interval before reinsertion is present in the literature) with extremely low rate of infection recurrence [154]. Additionally, ${ }^{99 \mathrm{~m}} \mathrm{Tc}$-ciprofloxacin results at the end of therapy had the highest sensitivity $(83 \%)$, accuracy $(70 \%)$ and negative predictive value $(95 \%)$ in predicting infection resolution or recurrence as compared to ESR assessment and clinical examinations [155]. $\mathrm{UBI}_{29-41}$ was also employed to differentiate infection from aseptic loosening of prostheses [156] as well as to assess response to antibiotic therapy with reduction in radiopharmaceutical uptake after treatment as compared to baseline scan in the responder group [157].

In conclusion radiolabeled leukocytes eventually combined with marrow imaging remains the technique of choice for diagnosing prosthetic joint infection with significant advantage in spatial resolution and differential diagnosis of bone/prosthesis from soft tissue involvement with SPECT/CT acquisitions. The value of $\left[{ }^{18} \mathrm{~F}\right]$ FDG-PET and PET/CT in this setting is still debatable and need further investigation. Despite the routine use of nuclear medicine procedure to evaluate and monitoring response to antimicrobial treatment, prospective studies to support such application are warrant.

\subsection{Cardiovascular System}

\subsubsection{Infective Endocarditis}

Infective endocarditis (IE), has dramatically changed over the last years both the etiology (from Streptococcus to Staphilococcus), predisponing conditions (rheumatic and congenital disease or syphilis are less frequent the underlying disease while mitral valve prolapsed, mitral and aortic valve calcifications, prosthetic valve and device, intravenous drug abuse are more frequently observed) and patients' population (younger patients). Diagnosis of IE is essentially clinical. Microbiological tests for germ characterization along with echocardiography (transthoracic, TTE and transesophageal, TEE) for the visualization of vegetation and local complications are needed to define the diagnosis according to the modified Dukes criteria (diagnosis categorized as definite, possible and rejected). In the New European Society of Cardiology 2015 modified criteria for the diagnosis of infective endocarditis molecular imaging techniques and computed tomography were also included to increase the likehood to reach a diagnosis [158]. Nuclear medicine has been demonstrated valuable in cases of undetermined echo findings (i.e. marantic vegetations, artifacts deriving from mechanical prosthesis or device's catheter) as well as for embolism detections. Furthermore, nuclear medicine might play a role for treatment management, since antimicrobial therapy discontinuation is empirically determined [159, 160].

Gallium-67 scintigraphy has been described by several authors for the detection of IE and myocardial abscess with a quite low specificity [161] while discordant results have been reported using radiolabeled WBC scintigraphy [162-167].

A meta-analysis of the literature from 1976 to 2005, (12 articles, referring to 378 patients, 380 lesions) defines ${ }^{99 \mathrm{~m}} \mathrm{Tc}$-labeled anti-granulocyte mAbs alone or in association with echocardiography the most accurate procedure for the detection of infective endocarditis (sensitivity $=100 \%$, specificity $=86 \%$ and accuracy $=92 \%$ with $89 \%$ positive predictive value) [168]. The real breakthrough for nuclear medicine procedure in IE and device related infection has reached with the introduction of SPECT/CT and PET/CT equipment: an exhaustive evaluation of the heart region is impossible without the possibility to acquire 3D images of the thorax. With such technology ${ }^{99 \mathrm{~m}}$ Tc-HMPAO labeled autologous leukocytes demonstrated the ability to accurately diagnosed cardiac and additional unsuspected extra-cardiac sites of infection up to $41 \%$ of the patients with IE $[169,170]$. No data are available for ${ }^{67} \mathrm{Ga}-$ SPECT/CT in IE, with the exception of a single case report [171]. More recently (all reports are published from 2010 underling the renewed interest in the field) favorable results with the use of $\mathrm{PET} / \mathrm{CT}$ with both in vitro $\left[{ }^{18} \mathrm{~F}\right] \mathrm{FDG}-\mathrm{WBC}$ (the first published series of patients included two IE and the same concerns described in the paragraph of FUO are true also for IE) and $\left[{ }^{18} \mathrm{~F}\right] \mathrm{FDG}$ were reported for the visualization of valve vegetation and the detection of distant embolism and metastatic site of infection (24-57\%) [123, 172-183] with high diagnostic performances (87\% sensitivity, 97\% specificity and $52 \%$ PPV) [174].

Particularly, in prosthetic valve endocarditis $\left[{ }^{18} \mathrm{~F}\right] \mathrm{FDG}$ uptake around a prosthetic valve has been introduced as new major criterion, increasing the sensitivity of the modified Duke criteria from 70 to $97 \%$ trought the reduction of "possible" IE [176]. Very recently, Rouzet et al. [182] compared $\left[{ }^{18} \mathrm{~F}\right] \mathrm{FDG}-\mathrm{PET} / \mathrm{CT}$ to ${ }^{99 \mathrm{~m}} \mathrm{Tc}-$ HMPAO WBC (planar + SPECT/CT images) in 39 patients with suspected prosthetic valve endocarditis. $\left[{ }^{18} \mathrm{~F}\right] \mathrm{FDG}-\mathrm{PET} / \mathrm{CT}$ resulted in a higher sensitivity (93\% versus $65 \%)$ but a lower specificy $(71 \%$ versus $100 \%)$ and accuracy ( $80 \%$ versus $86 \%$ ) compared to WBC imaging.

An additional promising role of $\left[{ }^{18} \mathrm{~F}\right] \mathrm{FDG}-\mathrm{PET} / \mathrm{CT}$ may be seen in patients with established IE, in whom it could be used to monitor response to antimicrobial treatment [184].

In order to avoid potential sources of false-positive findings in PET or PET/CT studies some considerations should be take into account in the imaging interpretation [185]. Variable focal of diffuse physiological $\left[{ }^{18} \mathrm{~F}\right] \mathrm{FDG}$ uptake is often observed in the normal myocardium (mainly in the left ventricle) of fasting non-diabetic patients (6-12 hours to overnight) with normal glucose levels [185, 186]. Many factors such as patients' age, fasting time, blood glucose levels, and a low-carbohydrate diet may influence myocardial $\left[{ }^{18} \mathrm{~F}\right] \mathrm{FDG}$ uptake $[185,187,188]$. Some approaches might be used to decrease myocardial $\left[{ }^{18} \mathrm{~F}\right] \mathrm{FDG}$ uptake including lowcarbohydrate diet [189] and very high-fat, low-carbohydrate, protein-permitted meal followed by fasting for 3-6 hours [190] before tracer injection [185, 187]. Alternatively, unfractionated heparin (50 IU/kg iv) which acts activating lipoprotein lipase and hepatic lipase, enhances plasma lipolytic activity and elevates plasma levels of FFA, could be administered before $\left[{ }^{18} \mathrm{~F}\right] \mathrm{FDG}$ injection $[185,191$, 192]. According to the SNMMI/ASNC/SCCT Guidelines [193] patients should be prepared with a fat-enriched diet lacking carbohydrates for $12-24 \mathrm{~h}$ prior to the scan, a $12-18$-h fast, and/or the 
use of intravenous heparin approximately 15 min prior to $\left[{ }^{18} \mathrm{~F}\right] \mathrm{FDG}$ injection [187].

The increased metabolic activity along the posterior aspect of the heart, where lipomatous hypertrophy of the interatrial septum may appear as a fat-containing mass with increased $\left[{ }^{18} \mathrm{~F}\right] \mathrm{FDG}$ uptake, could be another potential counfonding factor in the interpretation of PET/CT results $[185,194]$. Several different pathologic conditions such as active thrombi [186], soft atherosclerotic plaques [190], vasculitis [195], primary cardiac tumors [196], cardiac metastasis from a noncardiac tumor [197], postsurgical inflammation [198], and foreign body reactions [199] can mimic the pattern of focally increased $\left[{ }^{18} \mathrm{~F}\right] \mathrm{FDG}$ uptake that is typically observed in IE $[185,187]$. Therefore they should be considered in the differential diagnosis and excluded before diagnosis IE [185, 187]. A precise time-line after surgery has not been jet identified, at least 3 months from surgical procedure are suggested to minimize the risk of $\left[{ }^{18} \mathrm{~F}\right]$ FDG-PET/CT false positive results $[182,185,200]$. The patterns of $\left[{ }^{18} \mathrm{~F}\right] \mathrm{FDG}$ uptake and the anatomic changes observed at $\left[{ }^{18} \mathrm{~F}\right]$ FDG-PET/CT angiography in the early post-operative setting (i.e., after prosthetic valve or valve-tube graft surgery) have been recently reported [201] in order to help imagers to differentiate inflammation from infection [187]. Indeed, only an accurate patients selection and specfic inclusion criteria allow to achieve a high specificity for IE diagnosis using $\left[{ }^{18} \mathrm{~F}\right]$ FDG. Conversely, $\left[{ }^{18} \mathrm{~F}\right] \mathrm{FDG}-$ $\mathrm{PET} / \mathrm{CT}$ in patients with lower pretest probability would rely on the high negative predictive value of this imaging procedure [185, 187].

All together these data suggest a role of nuclear medicine imaging procedures for diagnosis confirmation of endocarditis particularly in presence of uncertainly echo findings, and for the exclusion of heart valve involvement during febrile episodes/sepsis in high risk patients, expecially in patients with prosthetic valve IE, as recently pointed out by the inclusion of nuclear medicine procedures in diagnostic flowcharts and clinical guidelines [158, 161]. The choice between a high specificity test as radiolabeled WBC (with SPECT/CT acquisition mandatory) or a high sensitive test as $\left[{ }^{18} \mathrm{~F}\right] \mathrm{FDG}-\mathrm{PET} / \mathrm{CT}$ is on the pre-test probability, patient clinical conditions and the elapsed time between the latest surgical event and the moleculr imaging test. For the detection of distant embolism and metastatic site of infections (with some costrains in the case of CNS embolisms if constrast medium is not applied) as well as for the monitoring of the antibiotic treatment response both radiolabeled WBC and $\left[{ }^{18} \mathrm{~F}\right] \mathrm{FDG}-\mathrm{PET} / \mathrm{CT}$ might be indicated, with some potential advantage of the latter due to higher spatial resolution and extremely high negative predictive value.

\subsubsection{Cardiovascular Implantable Electronic Devices}

Cardiac devices (CIED) infection occurs in 1\% and 7\% [202, 203]. CIED infection is associated with significant morbidity and mortality [204-207]. The main ethiological agents are Staphylococci $(60-80 \%)$; Gram-negative bacilli causes CIED infection in 5$10 \%$ of the cases, while cultures are negative in another $10 \%$ [5]. Fungeal or or mycobacteria infection is rare [5]. CIED-related infection may occur either as a surgical site infection within 1 year after implantation or as late-onset leading to endocarditis [5, 208, 209]. The contamination with cutaneous microorganisms when the pacemaker is implanted or the generator is revised results in early CIED infections $[5,210]$. The majority of infections begin in the surgical pocket. Infection extention may be underestimated in localized pocket infections. Local manifestations at the site of PM implantation are associated with infection of the intravascular part of the leads in up to $79 \%$ of cases $[5,211]$. Therefore, the extention of infection shoul alwayas be quantified. Systemic infection may be a consequence of a persistent infection that progress through the catheter leads involving the bloodstream and/or the endocardium or of a bacteremia originated in other foci, that then colonizes the leads, as occurs in healthcare related procedures [5, 207, 212]. Bacteriemia is almost unavoidably in CIED-related infection resulting often in metastatic foci [5]. Murdoc et al. [213] rerpoted that $10 \%$ of 2,781 episodes of IE were device-related endocarditis. Rarely conservative treatments with antimicrobial drugs are effective in CIED infection [214-216] which generally requires a complete removal of the hardware [217]. Nonetheless, device replacement for battery depletion or upgrades may become necessary some years after the first implantation [5]. Infection rates are higher in replacements compared to initial implantation [5, 202, 218, 219]. CIED infection diagnosis is generally based on microbiological assessment (blood cultures and culture of exudates from the pocket) and TEE, which may also be used to define patients' likelihood to have infection according to the Duke criteria/New European Society of Cardiology 2015 modified criteria [5, 158, 207]. However, it should be considered that such criteria have been originally developed for IE, therefore some appropriate implementations should be applied in suspected CIED infections. Nevertheless, underestimation of the extent of CIED infection it is possible even when introducing these corrections. In fact, the lead portion between pocket and superior cava debouchment may not be accurately explored by TEE [4]. Some radiological findings such as the presence of fluid density between the heart and the device, although not specific since they can be observed also in the postoperative or inflammatory noninfectious changes, may be suggestive for CIED infection $[5,207,220]$. Additonally, CIED infection cannot be rule out in case of the absence of crumpling of patches in plain X-ray, or fluid around the heart in the CT scan [5]. Nuclear medicine imaging techniques have been applied to evaluate suspected or ascertained CIED infection altought the level of evidence of the published remains relatively low (Level II, class C) $[151] .{ }^{67}$ Ga-citrate scan has been successfully employed in CIED infection [5, 221, 222]. Radiolabaled WBC scintigraphy helps to define the presence and the extent of CIED infection [5, 223-226]. The anatomic location and extent of a suspected infection has been precisely identified and detected by WBC SPECT/CT, improving patients' management [5, 170, 226]. Additionally WBC SPECT/CT has bee reported to be useful to detected additional unsuspected extracardiac sites of infection in device-related sepsis, although with some limitations in case of small CNS embolism [5, 170]. Similar results have been published in lead-associated infection using ${ }^{99 \mathrm{~m}} \mathrm{Tc}$-sulesomab SPECT/CT [5, 227]. $\left[{ }^{18}\right.$ F]FDG-PET/CT has been also used to identify CIED infection with promising results [228, 229] particularly when it is performed to rule out device involvement during infection $[5,230]$ and to define the embolic burden [5, 230-233]. Ad-hoc diagnostic criteria have been proposed by Serrazin et al. [234] to improve the diagnostic performances of $\left[{ }^{18} \mathrm{~F}\right] \mathrm{FDG}-\mathrm{PET} / \mathrm{CT}$ in CIED infections. Dual-point PET/CT (standard plus 3 hours images) seems to be promising particularly in case of lead infection [235]. A dual-point approach with standard plus delayed (3 hours) images has been evalauted also in this specific clinical field with promising results particularly in case of lead infection [235]. However, as for IE, a positive $\left[{ }^{18} \mathrm{~F}\right] \mathrm{FDG}-\mathrm{PET} / \mathrm{CT}$ scan should be carefully interpreted $[5,185]$. Additionally, postsurgical changes and inflammatory reaction to foreign material (as in a Dacron pouch) [234] should always be considered in the differential diagnosis of CIED infection, especially in early infection [5]. Furthermore, when used to guide discontinuation of antibiotic treatment $\left[{ }^{18} \mathrm{~F}\right] \mathrm{FDG}$ $\mathrm{PET} / \mathrm{CT}$ relies on extremely high negative predictive value, thus a negative scan is mandatory. False negative cases due to antimicrobial treatment can occur [5]. The great potential of radionuclide imaging is mostly to be seen in the differential diagnosis between pocket hematoma and purulent collection, fibrous casts or thrombus and active vegetations detected by TEE on leads, and in the definition of disease extent when in the presence of ascertained pocket infection [5].

\subsubsection{Vascular Graft Infection}

Vascular prosthesis infection (VPI) occurs in $0.5-5 \%$ of implantations [5]. Staphylococcus aureus, Escherichia coli and S. epidermidis are responsible of the majority of cases whereas, Klebsiella, 
Pseudomonas, Enterobacter and Proteus accounts for most of the remaining cases $[1,236]$. Surgery associated to antimicrobial therapy is the treatment of choice if there are no contraindication for surgery, while antimicrobial therapy alone may be the only option in high-risk patients [1]. An early diagnosis is closely assosciated to the success of the treatment. CT angiography is the technique of choice for both infection confirmation and complication detection (sensitivity $85-100 \%$ ) [1]. Nuclear medicine and MRI are used in unclear situation when CT sensitivity decrease (as in low-grade infection or in early infection) [1]. ${ }^{67}$ Ga-citrate, radiolabeled HIG, radiolabeled WBC (either with ${ }^{99 \mathrm{~m}} \mathrm{Tc}$ or ${ }^{111} \mathrm{In}$ ), and labeled antigranulocyte antibodies have been used in VPI. ${ }^{99 \mathrm{~m}}$ Tc-labeled autologous leukocytes resulted better than other diagnostic methods including CT (sensitivity $82-100 \%$ versus $75 \%$, specificity $85-$ $100 \%$ versus $57 \%$, respectively) in prosthetic graft infection [237]. This superiority over other methods has been heightened by SPECT/CT that allows to characterize pathological site of infection and to define its extension, to exclude false positive results such as bowel aspecific tracer accumulation, and to confirm or reject graft involvement even in presence of post-surgical distortions and complex anatomical sites [1, 18, 121, 238, 239] (Fig. 5). High specificity is maintained even when scintigraphy is performed during the first month after surgery $[1,239,240]$. When the abdominal region is included in the study and ${ }^{99 \mathrm{~m}}$ Tc-HMPAO WBC used, methodological efforts (i.e., adequate image acquisition time) are necessary to decrease false positive findings [1]. ${ }^{111}$ In-WBC scintigraphy has been reported to perform similar to MRI (positive and negative predictive value of $80 \%$ and $82 \%$ for ${ }^{111}$ In-WBC and $95 \%$ and $80 \%$ for MRI) [241]. WBC scintigraphy may be used to determine the response to treatment, preventing the risk of adverse drug reactions related to long-lasting regimens as well as the acquisition of resistance in patients treated with long-term suppressive antibiotic treatment [1, 239, 242].

${ }^{99 \mathrm{~m}} \mathrm{Tc}$-Fanolesomab (approved in the United States for equivocal presentation of appendicitis, but withdrawn from the market in late 2005 following postmarketing reports of serious adverse events, including two fatalities) was shown to diagnose prosthetic vascular graft infection with an accuracy of 95\% [243].

$\left[{ }^{18} \mathrm{~F}\right]$ FDG-PET/CT may be considered a valuable method to evaluate suspected VPI [1, 244, 245]. Good diagnostic performances have been reported for $\left[{ }^{18} \mathrm{~F}\right] \mathrm{FDG}$ images (sensitivity $91 \%$ and specificity $64 \%$ versus $64 \%$ and $86 \%$ for CT scan), significantly improved adopting appropriate interpretation criteria (focal $\left[{ }^{18} \mathrm{~F}\right]$ FDG uptake) $[1,246]$. In fact, inhomogeneous $\left[{ }^{18} \mathrm{~F}\right] \mathrm{FDG}$ uptake is an unspecific finding that may be related either to very low grade infection, weak immune reaction, inflammatory conditions such as vasculitis and atherosclerosis, chronic aseptic inflammation, and post-surgical changes that may persist for years after the prosthesis implantation $[1,247]$. Potential pitfalls related to $\left[{ }^{18} \mathrm{~F}\right] \mathrm{FDG}$ uptake over time in noninfected implants have been described in relationship to the prosthetic material and the location [1]. GoreTex graft rae characterized by homogeneous pattern whereas the inhomogeneous uptake has been reported more in Dacron ones (none of the grafts demonstrated focal uptake). Uptake intensity was significantly higher in Dacron than in Gore-Tex and native vein grafts. Native vein grafts showed a significant decrease in $\left[{ }^{18} \mathrm{~F}\right]$ FDG uptake over time whereas synthetic grafts showed no change in intensity for during follow-up (up to 16 years) [1, 248]. The use of PET/CT increased sensitivity to $93 \%$, specificity to 70 $91 \%$ (positive and negative predictive values of $82-88 \%$ and 88 $96 \%$ ) [249], mainly as a consequence of the better anatomical localization [1]. Dual-time-point images seems to be useful to detect aortic graft infection, improving image quality, and enhancing delineation of the infected aortic grafts $[1,250]$. A high rate of false positive results has been reported using both patterns of ${ }^{18} \mathrm{~F} \mid \mathrm{FDG}$ uptake (SUVmax, tissue to background ratio, visual grading scale, and focality of $\left[{ }^{18} \mathrm{~F}\right]$ FDG uptake) and CT features (graft wall thickening, oedema, gas surrounding the graft or any other sights) [251] due to the fact that they may largely overlap either in infected or uninfected vascular grafts $[1,252,253]$. More recently a new five point visual grading $\left[{ }^{18} \mathrm{~F}\right] \mathrm{FDG}$ score which resulted in a very high accuracy has been proposed [254]. Nevertheless, Spacek et al. [255] identified focal $\left.{ }^{18} \mathrm{~F}\right] \mathrm{FDG}$ uptake and irregular graft boundary at CT images as independent significant predictors of low-grade VPI (erroneous classification occurring in $<5 \%$ in the majority of patients).

$\left[{ }^{18} \mathrm{~F}\right]$ FDG-PET/CT may also be used to monitor antimicrobial treatment as shown by Husmann et al. [256]. They prospectively evaluated 25 patients with proven VPI performing baseline and follow-up (89-249 day after the baseline) PET/CT examinations. $\Gamma^{18}$ FjFDG-PET/CT had an impact on management in all patients: antibiotic treatment was continued in $76 \%$ of cases (persistent
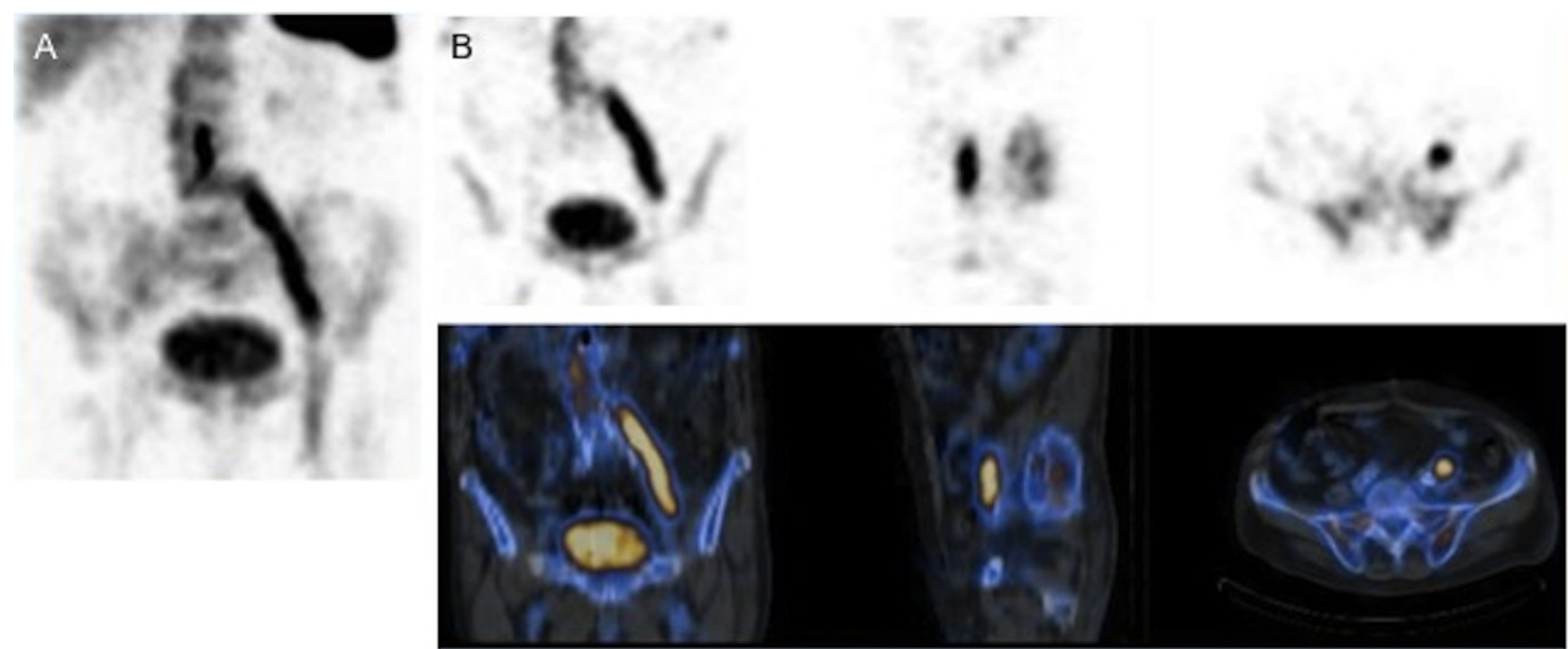

Fig. (5). ${ }^{99 \mathrm{~m}} \mathrm{Tc}-\mathrm{HMPAO} \mathrm{WBC}$ in a patient with aorto-bisiliac vascular graft. MIP images (A) and SPECT/CT images (B upper panel emission, lower panel fused SPECT-CT, from left to right coronal, sagittal and transaxial images, respectively) show the presence of intense and diffuse radiolabeled leukocyte uptake all along the distal aortic and the left bisiliac branches of the vascular graft. 
$\left[{ }^{18} \mathrm{~F}\right] \mathrm{FDG}$ uptake) while was stopped or changed in $8 \%$ and $16 \%$ of patients, respectively. In $32 \%$ of patients, Additional incidental findings were detected in $32 \%$ of cases by follow-up $\left[{ }^{18} \mathrm{~F}\right] \mathrm{FDG}$ $\mathrm{PET} / \mathrm{CT}$ further impacting on patient management.

In conclusion, radiolabeled autologous leukocyte scintigraphy is the 'gold standard' for vascular graft infection diagnosis and treatment monitoring since the high sensitivity and specificity; SPECT/CT acquisition should be mandatory since it increases the diagnostic accuracy reducing the possibility of false positive results [1]. $\left[{ }^{18} \mathrm{~F}\right] \mathrm{FDG}-\mathrm{PET} / \mathrm{CT}$ may provide a valid alternative to $\mathrm{WBC}$ scan when adopting appropriate criteria for imaging interpretation. Still, no data on its the use in the early phase of post-surgical setting are currently available [1].

\subsection{Abdominal Infection}

\subsubsection{Abdominal Abscess}

Abdominal abscess, a pocket of inflamed tissue filled with pus or infected fluid, that can occur as consequence of a number of different causes, rapresents a serious problem in surgical practice [4]. The appropriate treatment of abdominal abscess is often delayed due to the obscure nature of many conditions resulting in abscess formation, which can make diagnosis and localization difficult [4]. Ultrasound, in experienced hands, has an accuracy rate greater than $90 \%$ [257] except in case of retroperitoneal or midabdominal abscess. CT scan is the best diagnostic method since its high accuracy $(>95 \%)[5,258]$. Gallium scan has been compared to $\mathrm{CT}$ in the detection of intra-abdominal abscess after colorectal surgery (sensitivity, specificity and accuracy of $100 \%, 78 \%$ and $91 \%$, respectively versus $93 \%, 100 \%$, and $96 \%$ ) [223, 259]. Leukocyte scintigraphy is sensitive in detecting abdominal abscess in different locations (76-100\% sensitivity, $85-100 \%$ specificity, $88-100 \%$ accuracy) [260] except for the liver and spleen due to physiological localization of labeled cells in these organs [261]. The addition of ${ }^{99 \mathrm{~m}} \mathrm{Tc}$-sulfur colloid liver-spleen scan to the WBC increases the sensitivity of the WBC scan in the detection of hepatosplenic infections [260, 262]. Furthermore, WBC scintigraphy can reveal unsuspected extra-abdominal sites of infection [260,263]. WBC scan has been reported to be helpful in intra-abdominal infection patient management in $76 \%$ of cases $[260,264]$. False positive results have been described in the early postoperative period due to non-specific postsurgical inflammatory uptake $[198,260]$.

Synthetic mesh is used commonly in the repair of abdominal wall herniopathy, one of the most common operation. Infection at the surgical site where mesh is present, is an important clinical problem (1-2\% cases/years). For late mesh infection following incisional hernia repair, particularly for silent abdominal wall infections after surgery radiolabeled antigranulocyte antibodies represented a useful method for the detection of infection and subsequent appropriate therapy $[116,265]$.

$\left[{ }^{18}\right.$ F]FDG PET/CT has been used in the diagnosis of cyst infection in patients with autosomal dominant polycystic kidney disease, proving the ability to define cyst infection in $84.6 \%$ of patients and revealing other source of infection in $64 \%$ [266]. Intense $\left[{ }^{18} \mathrm{~F}\right] \mathrm{FDG}$ uptake have been also reported in mendelian and complex inflammatory disorders. At the time of relapse, it can be used to differentiate between a sequela of previous flares and a new localization [267].

\subsubsection{Appendicitis}

Inflammation in the appendix requires immediate medical attention. Many nuclear medicine techniques including ${ }^{99 \mathrm{~m}} \mathrm{Tc}-$ HMPAO or ${ }^{111}$ In oxine autologous leukocytes, ${ }^{99 \mathrm{~m}} \mathrm{Tc}-\mathrm{HIG},{ }^{99 \mathrm{~m}} \mathrm{Tc}$ mAbs $\left({ }^{99 \mathrm{~m}}\right.$ Tc-anti-CD15, LeuTech ${ }^{\circledR} ;{ }^{99 \mathrm{~m}}$ Tc-BW 250/183, Granuloscint $\left({ }^{99 \mathrm{~m}} \mathrm{Tc}\right.$ sulesomab, Leukoscan $\left.{ }^{\circledR}\right)$ can be indistinctly used since their high accuracy. Annovazzi et al. [237], evaluated articles published between 1987 to 2004 (24 papers for a total of 1548 patients) demonstrating radiolabeled $\mathrm{mAbs}$ as the radiopharmaceutical of choice for the diagnosis of appendicitis since with this radiopharmaceutical prevent time waste. ${ }^{99 \mathrm{~m}}$ Tc-Fanolesomab, was approved in the United States for use in patients with equivocal presentation of appendicitis in 2004, but soon withdrawn from the market since serious adverse events occurrence, including two fatalities [268].

More recently, Reavey et al. [269] described the patterns of normal pediatric bowel $\left[{ }^{18} \mathrm{~F}\right] \mathrm{FDG}$ activity with specific regard within the appendix in order to avoid misinterpretation of images. They concluded that $\left[{ }^{18} \mathrm{~F}\right] \mathrm{FDG}$ uptake in the appendix is typically similar to that of background activity, however, since children have more active lymphoid tissue than adults, slight variations in appendiceal $\left[{ }^{18} \mathrm{~F}\right] \mathrm{FDG}$ uptake do occur which should not be misinterpreted as pathological.

\section{CONCLUSION}

Nuclear Medicine imaging has diagnostic, prognostic and therapeutic impacts on infectious diseases. Different techniques and radiotracers may be used based on the diseases' patho-biochemical features and the clinical need. Technological improvements result in innovative equipment that has increased spatial resolution of nuclear medicine modalities. The appropriate definition of the role of each procedure in diagnostic/therapeutic clinical algorithms is the next challenge. This process is on-going by the European Association of Nuclear Medicine (EANM) in collaboration with several other European societies and, as a result, several procedural and joint guidelines have been already published [261-266].

\section{CONSENT FOR PUBLICATION}

Not applicable.

\section{CONFLICT OF INTEREST} wise.

The authors declare no conflict of interest, financial or other-

\section{ACKNOWLEDGEMENTS}

Declared none.

\section{REFERENCES}

[1] Erba PA. Erba PA. Imaging cardiovascular infection - Groningen: s.n 2013 [cited 2017 Dec 13]. Available from: https: //www.rug.nl/research/portal/files/14424424/Imaging_cardiovascul ar infecti 1.pdf

[2] Malviya G, De Vries EF, Dierckx RA, Signore A. Radiopharmaceuticals for Imaging Chronic Lymphocytic Inflammation Brazilian Arch Biol Technol 2007; 50: 1-13.

[3] Pineda C, Vargas A, Rodríguez AV. Imaging of osteomyelitis: current concepts Infect. Dis Clin North Am 2006; 20(4): 789-825.

[4] Pineda C, Espinosa R, Pena A. Radiographic imaging in osteomyelitis: the role of plain radiography, computed tomography, ultrasonography, magnetic resonance imaging, and scintigraphy. Semin Plast Surg 2009; 23(2): 80-9.

[5] Lazzeri E, Signore A, Erba PA, et al. Radionuclide imaging of infection and inflammation: A pictorial case-based atlas. Springer; 2013 [cited 2017 Dec 13].

[6] Erba PA, Israel O. SPECT/CT in infection and inflammation. Clin Transl Imaging 2014; 2: 519-35.

[7] Jaramillo D, Treves ST, Kasser JR, Harper M, Sundel R, Laor T. Osteomyelitis and septic arthritis in children: Appropriate use of imaging to guide treatment 1995. AJR Am J Roentgenol 1995; 165(2): 399-403.

[8] Horger M, Eschmann SM, Pfannenberg C, et al. Added value of SPECT/CT in patients suspected of having bone infection: preliminary results. Arch Orthop Trauma Surg 2007; 127: 211-21.

[9] Rini JN, Palestro CJ. Imaging of infection and inflammation with 18F-FDG-labeled leukocytes. Q. J Nucl Med Mol 2006; 50: 143-6.

[10] Prandini N, Lazzeri E, Rossi B, Erba P, Parisella MG, Signore A. Nuclear medicine imaging of bone infections. Nucl Med Commun 2006; 27(8): 633-44. 
[11] Wanahita A, Villeda C, Kutka N, Ramirez J, Musher D. Diagnostic sensitivity and specificity of the radionuclide (indium)-labeled leukocyte scan. J Infect 2007; 55: 214-9.

[12] Wang G, Zhao K, Liu Z, Dong M, Yang S. A meta-analysis of fluorodeoxyglucose-positron emission tomography versus scintigraphy in the evaluation of suspected osteomyelitis. Nucl Med Commun 2011; 32(12): 1134-42.

[13] Al-Zahrani A, El-Saban K, Al-Sakhri H. Diagnosis of bone infection by complementary role of technetium-99m MDP and technetium-99m hexamethylpropylene-amineoxime-leukocytes. Indian $\mathrm{J}$ Nucl Med 2012; 27(3): 164-71.

[14] Glaudemans AW, de Vries EF, Vermeulen LE, Slart RH, Dierckx RA, Signore A. A large retrospective single-centre study to define the best image acquisition protocols and interpretation criteria for white blood cell scintigraphy with 99mTc-HMPAO-labelled leucocytes in musculoskeletal infections. Eur J Nucl Med Mol 2013; 40: 1760-9.

[15] Image acquisition and interpretation criteria for (99m)Tc-HMPAOlabelled white blood cell scintigraphy: results of a multicentre study. Eur J Nucl Med Mol Imaging 2014; 41: 615-23.

[16] Pakos EE, Koumoullis HD, Koumoulis HD, Fotopoulos AD, Ioannidis JP. steomyelitis: Antigranulocyte scintigraphy with $99 \mathrm{mTC}$ radiolabeled monoclonal antibodies for diagnosis-- meta-analysis. Radiology 2007; 245: 732-41.

[17] Richter WS, Ivancevic V, Meller J, et al. 99mTc-besilesomab (Scintimun) in peripheral osteomyelitis: comparison with $99 \mathrm{mTc}-$ labelled white blood cells. Eur J Nucl Med Mol Imaging 2011; 38: 899-910.

[18] Bar-Shalom R, Yefremov N, Guralnik L, et al. SPECT/CT using $67 \mathrm{Ga}$ and $111 \mathrm{In}$-labeled leukocyte scintigraphy for diagnosis of infection. J Nucl Med 2006; 47: 587-94.

[19] Filippi L, Schillaci O. Usefulness of hybrid SPECT/CT in 99mTcHMPAO-labeled leukocyte scintigraphy for bone and joint infections. J Nucl Med 2006; 47: 1908-13.

[20] Graute V, Feist M, Lehner S, et al. Detection of low-grade prosthetic joint infections using 99mTc-antigranulocyte SPECT/CT: initial clinical results. Eur J Nucl Med Mol Imaging 2010; 37: 1751-9.

[21] Gutfilen B, Lopes de Souza SA, Martins FP, Cardoso LR, Pinheiro Pessoa MC, Fonseca LM. Use of 99mTc-mononuclear leukocyte scintigraphy in nosocomial fever. Acta Radiol 2006; 47: 699-704.

[22] Mora Ríos FG, Isunza Ramírez A, López Marmolejo A, Palma Rosillo RM, Guízar Cuevas S, Mora Magaña I, et al. Sensitivity and specificity of the Tc-99m ciprofloxacin scan in pediatric osteomyelitis. Acta ortopédica Mex 2010; 24: 248-51.

[23] Dumarey N, Blocklet D, Appelboom T, Tant L, Schoutens A. Infecton is not specific for bacterial osteo-articular infective pathology Schoutens A. Infecton is not specific for bacterial osteo-articular infective pathology. Eur J Nucl Med Mol Imaging 2002; 29: 530-5.

[24] Hall AV, Solanki KK, Vinjamuri S, Britton KE, Das SS. Evaluation of the efficacy of $99 \mathrm{mTc}-$ Infecton, a novel agent for detecting sites of infection. J Clin Pathol 1998; 51: 215-9.

[25] Sonmezoglu K, Sonmezoglu M, Halac M, et al. Usefulness of $99 \mathrm{mTc}$-ciprofloxacin (infecton) scan in diagnosis of chronic orthopedic infections: comparative study with 99mTc-HMPAO leukocyte scintigraphy. J Nucl Med 2001; 42: 567-74.

[26] Welling MM, Lupetti A, Balter HS, et al. $99 \mathrm{mTc}$-labeled antimicrobial peptides for detection of bacterial and Candida albicans infections. J Nucl Med 2001; 42: 788-94.

[27] Sarda L, Saleh-Mghir A, Peker C, Meulemans A, Crémieux A-C, Le Guludec D. Evaluation of (99m)Tc-ciprofloxacin scintigraphy in a rabbit model of Staphylococcus aureus prosthetic joint infection. J Nucl Med 2002; 43: 239-45

[28] Yapar Z, Kibar M, Yapar AF, Toğrul E, Kayaselçuk U, Sarpel Y. The efficacy of technetium-99m ciprofloxacin (Infecton) imaging in suspected orthopaedic infection: A comparison with sequential bone/gallium imaging. Eur J Nucl Med 2001; 28: 822-30.

[29] Crémieux AC, Mghir AS, Bleton R, et al. Efficacy of sparfloxacin and autoradiographic diffusion pattern of [14C]Sparfloxacin in experimental Staphylococcus aureus joint prosthesis infection. Antimicrob. Agents Chemother 1996; 40: 2111-6.

[30] Nanni C, Errani C, Boriani L, et al. 68Ga-citrate PET/CT for evaluating patients with infections of the bone: preliminary results. $\mathrm{J}$ Nucl Med 2010; 51: 1932-6.
[31] Van Acker F, Nuyts J, Maes A, et al. FDG-PET, 99mtc-HMPAO white blood cell SPET and bone scintigraphy in the evaluation of painful total knee arthroplasties. Eur J Nucl Med 2001; 28: 1496504.

[32] Vanquickenborne B, Maes A, Nuyts J, et al. The value of (18)FDGPET for the detection of infected hip prosthesis. Eur J Nucl Med Mol Imaging 2003; 30: 705-15.

[33] Palestro CJ. Nuclear medicine and the failed joint replacement: Past, present, and future. World J Radiol 2014; 6: 446-58.

[34] Guhlmann A, Brecht-Krauss D, Suger G, et al. Fluorine-18-FDG PET and technetium-99m antigranulocyte antibody scintigraphy in chronic osteomyelitis. J Nucl Med 1998; 39: 2145-52.

[35] de Winter F, van de Wiele C, Vogelaers D, de Smet K, Verdonk R, Dierckx RA. Fluorine-18 fluorodeoxyglucose-position emission tomography: A highly accurate imaging modality for the diagnosis of chronic musculoskeletal infections. J Bone Joint Surg Am 2001; 83-A: 651-60.

[36] Termaat MF, Raijmakers PG, Scholten HJ, Bakker FC, Patka P, Haarman HJ. The accuracy of diagnostic imaging for the assessment of chronic osteomyelitis: A systematic review and metaanalysis. J. Bone Joint Surg. Am 2005; 87: 2464-71.

[37] Hartmann A, Eid K, Dora C, Trentz O, von Schulthess GK, Stumpe KD. Diagnostic value of 18F-FDG PET/CT in trauma patients with suspected chronic osteomyelitis. Eur J Nucl Med Mol Imaging 2007; 34: 704-14.

[38] Stecker FF, Schierz J-H, Opfermann T, et al. Early dynamic 18FFDG PET/CT to diagnose chronic osteomyelitis following lower extremity fractures. A pilot study. Nuklearmedizin 2014; 53: 11722 .

[39] Freesmeyer M, Stecker FF, Schierz JH, Hofmann GO, Winkens T. First experience with early dynamic (18)F-NaF-PET/CT in patients with chronic osteomyelitis. Ann Nucl Med 2014; 28: 314-21.

[40] Loop FD, Lytle BW, Cosgrove DM, et al. J. Maxwell Chamberlain memorial paper. Sternal wound complications after isolated coronary artery bypass grafting: early and late mortality, morbidity, and cost of care. Ann Thorac Surg 1990; 49: 179-86-7.

[41] Quirce R, Carril JM, Gutiérrez-Mendiguchía C, Serrano J, Rabasa JM, Bernal JM. Assessment of the diagnostic capacity of planar scintigraphy and SPECT with 99mTc-HMPAO-labelled leukocytes in superficial and deep sternal infections after median sternotomy. Nucl Med Commun 2002; 23: 453-9.

[42] Martin RD, Rieckenbrauck N. The role of the bone-gallium scan in sternal osteomyelitis. Ann Plast Surg 1993; 30(4): 320-2.

[43] Papós M, Nehéz I, Simonfalvi I, Kovács G, Csernay L, Pávics L. Diagnostic value of $99 \mathrm{mTc}-\mathrm{HM}-\mathrm{PAO}$ leukocyte scintigraphy and computer tomography in patients with sternal wound infections. Nucl Med Rev Cent East Eur 2000; 3: 35-9.

[44] Weon YC, Yang SO, Choi YY, et al. Use of Tc-99m HMPAO leukocyte scans to evaluate bone infection: incremental value of additional SPECT images. Clin Nucl Med 2000; 25(7): 519-26.

[45] Rouzet F, de Labriolle-Vaylet C, Trouillet JL, et al. Diagnostic value of $99 \mathrm{mTc}-\mathrm{HMPAO}$-labeled leukocytes scintigraphy in suspicion of post-sternotomy mediastinitis relapse. J Nucl Cardiol 2015; 22: 123-9.

[46] Koorbusch GF, Fotos P, Goll KT. Retrospective assessment of osteomyelitis. Oral Surg Oral Med Oral Pathol 1992; 74(2): 149-54.

[47] Bernier S, Clermont S, Maranda G, Turcotte JY. Osteomyelitis of the jaws. J Can Dent Assoc 1995; 61: 441-2, 445-8.

[48] Hudson JW. Osteomyelitis of the jaws: A 50-year perspective. J Oral Maxillofac Surg 1993; 51: 1294-301.

[49] Schuknecht B, Valavanis A. Osteomyelitis of the mandible. Neuroimaging Clin N Am 2003; 13(3): 605-18.

[50] Sasaki J, Nameta K. Chronic osteomyelitis of mandibulae. Nihon Rinsho 1994; 52: 507-11.

[51] Ida M, Watanabe H, Tetsumura A, Kurabayashi T. CT findings as a significant predictive factor for the curability of mandibular osteomyelitis: multivariate analysis. Dentomaxillofac Radiol 2005; 34(2): 86-90.

[52] Davies HT, Carr RJ. Osteomyelitis of the mandible: A complication of routine dental extractions in alcoholics. Br J Oral Maxillofac Surg 1990; 28(3): 185-8 
[53] Reinert S, Widlitzek H, Venderink DJ. The value of magnetic resonance imaging in the diagnosis of mandibular osteomyelitis. $\mathrm{Br} \mathrm{J}$ Oral Maxillofac Surg 1999; 37(6): 459-63.

[54] Fukumitsu N, Ujigawa K, Mori Y, et al. What can be identified by three-phase bone scintigraphy in patients with chronic osteomyelitis of the mandible? Ann Nucl Med 2010; 24(4): 287-93.

[55] Boronat-Ferrater M, Simó-Perdigó M, Cuberas-Borrós G, et al. Bone scintigraphy and radiolabeled white blood cell scintigraphy for the diagnosis of mandibular osteomyelitis. Clin Nucl Med 2011; 36(4): 273-6.

[56] Bolouri C, Merwald M, Huellner MW, et al. Performance of orthopantomography, planar scintigraphy, CT alone and SPECT/CT in patients with suspected osteomyelitis of the jaw. Eur J Nucl Med Mol Imaging 2013; 40: 411-7.

[57] Bruni C, Padovano F, Travascio L, Schillaci O, Simonetti G. Usefulness of hybrid SPECT/CT for the 99mTc-HMPAO-labeled leukocyte scintigraphy in a case of cranial osteomyelitis. Braz J Infect Dis 2008; 12: 558-60.

[58] Chakraborty D, Bhattacharya A, Gupta AK, Panda NK, Das A, Mittal BR. Skull base osteomyelitis in otitis externa: The utility of triphasic and single photon emission computed tomography/computed tomography bone scintigraphy. Indian J Nucl Med 2013; 28: 65-9.

[59] Sharma P, Agarwal KK, Kumar S, et al. Utility of (99m)Tc-MDP hybrid SPECT-CT for diagnosis of skull base osteomyelitis: comparison with planar bone scintigraphy, SPECT, and CT. Jpn J Radiol 2013; 31:81-8.

[60] Lee S, Hooper R, Fuller A, Turlakow A, Cousins V, Nouraei R. Otogenic cranial base osteomyelitis: A proposed prognosis-based system for disease classification. Otol Neurotol 2008; 29(5): 66672.

[61] Zanglis A, Andreopoulos D, Dima M, Baltas G, Baziotis N. Jaw uptake of technetium-99 methylene diphosphonate in patients on biphosphonates: A word of caution. Hell J Nucl Med 2007; 10(3): 177-80.

[62] Hakim SG, Bruecker CW, Jacobsen HC, et al. The value of FDGPET and bone scintigraphy with SPECT in the primary diagnosis and follow-up of patients with chronic osteomyelitis of the mandible. Int J Oral Maxillofac Surg 2006; 35(9): 809-16.

[63] Lazzeri E, Erba P, Perri M, Doria R, Tascini C, Mariani G. Clinical impact of SPECT/CT with In-111 biotin on the management of patients with suspected spine infection. Clin Nucl Med 2010; 35: 127.

[64] Lazzeri E. Nuclear Medicine imaging of vertebral infections: role of radiolabelled biotin s.n 2009. Available from: https: //www.rug.nl/research/portal/files/14495809/c7.pdf

[65] Signore A. Diagnostic imaging of infections and inflammatory diseases: A multidisciplinary approach. John Wiley \& Sons, Inc; 2014.

[66] Grane P, Josephsson A, Seferlis A, Tullberg T. Septic and aseptic post-operative discitis in the lumbar spine--evaluation by MR imaging. Acta Radiol 1998; 39: 108-15.

[67] Wolansky LJ, Heary RF, Patterson T, et al. Pseudosparing of the endplate: A potential pitfall in using MR imaging to diagnose infectious spondylitis. AJR Am J Roentgenol 1999; 172(3): 777-80.

[68] Wagner SC, Schweitzer ME, Morrison WB, Przybylski GJ, Parker L. Can imaging findings help differentiate spinal neuropathic arthropathy from disk space infection? Initial experience. Radiology 2000; 214(3): 693-9.

[69] Balériaux DL, Neugroschl C. Spinal and spinal cord infection. Eur Radiol 2004; 14 Suppl 3: E72-83.

[70] Chew FS, Kline MJ. Diagnostic yield of CT-guided percutaneous aspiration procedures in suspected spontaneous infectious diskitis. Radiology 2001; 218: 211-4.

[71] Dullerud R, Nakstad PH. Side effects and complications of automated percutaneous lumbar nucleotomy. Neuroradiology 1997; 39(4): 282-5.

[72] Rosen RS, Fayad L, Wahl RL. Increased 18F-FDG uptake in degenerative disease of the spine: Characterization with $18 \mathrm{~F}-\mathrm{FDG}$ PET/CT. J Nucl Med 2006; 47: 1274-80.

[73] Fuster D, Tomás X, Mayoral M, et al. Prospective comparison of whole-body (18)F-FDG PET/CT and MRI of the spine in the diag- nosis of haematogenous spondylodiscitis. Eur J Nucl Med Mol Imaging 2015; 42: 264-71.

[74] Ito K, Kubota K, Morooka M, Hasuo K, Kuroki H, Mimori A. Clinical impact of (18)F-FDG PET/CT on the management and diagnosis of infectious spondylitis. Nucl Med Commun 2010; 31: 691-8.

[75] Nakahara M, Ito M, Hattori N, et al. 18F-FDG-PET/CT better localizes active spinal infection than MRI for successful minimally invasive surgery. Acta Radiol 2015; 56: 829-36.

[76] Kim SJ, Kim IJ, Suh KT, Kim YK, Lee JS. Prediction of residual disease of spine infection using F-18 FDG PET/CT. Spine (Phila. Pa. 1976) 2009; 34: 2424-30.

[77] Nanni C, Boriani L, Salvadori C, et al. FDG PET/CT is useful for the interim evaluation of response to therapy in patients affected by haematogenous spondylodiscitis. Eur J Nucl Med Mol Imaging 2012; 39: 1538-44.

[78] Ioannou S, Chatziioannou S, Pneumaticos SG, Zormpala A, Sipsas NV. Fluorine-18 fluoro-2-deoxy-D-glucose positron emission tomography/computed tomography scan contributes to the diagnosis and management of brucellar spondylodiskitis. BMC Infect Dis 2013; 13: 73 .

[79] Niccoli Asabella A, Iuele F, Simone F, et al. Role of (18)F-FDG $\mathrm{PET} / \mathrm{CT}$ in the evaluation of response to antibiotic therapy in patients affected by infectious spondylodiscitis. Hell J Nucl Med 2016; (18 Suppl 1): 17-22.

[80] Riccio SA, Chu AK, Rabin HR, Kloiber R. Fluorodeoxyglucose positron emission tomography/computed tomography interpretation criteria for assessment of antibiotic treatment response in pyogenic spine infection. Can Assoc Radiol J 2015; 66: 145-52.

[81] Dillmann-Arroyo C, Cantú-Leal R, Campa-Núñez H, LópezCavazos C, Bermúdez-Argüelles M, Mejía-Herrera JC. Application of the ubiquicidin 29-41 scan in the diagnosis of pyogenic vertebral osteomyelitis. Acta ortopédica Mex 2011; 25: 27-31.

[82] Lazzeri E, Erba P, Perri M, et al. Scintigraphic imaging of vertebral osteomyelitis with 111 in-biotin. Spine (Phila. Pa. 1976) 2008; 33: E198-204.

[83] Maurer AH, Millmond SH, Knight LC, et al. Infection in diabetic osteoarthropathy: use of indium-labeled leukocytes for diagnosis Infection in diabetic osteoarthropathy: use of indium-labeled leukocytes for diagnosis. Radiology 1986; 161: 221-5.

[84] Keenan AM, Tindel NL, Alavi A. Diagnosis of pedal osteomyelitis in diabetic patients using current scintigraphic techniques. Arch Intern Med 1989; 149: 2262-6.

[85] Larcos G, Brown ML, Sutton RT. Diagnosis of osteomyelitis of the foot in diabetic patients: value of $111 \mathrm{In}$-leukocyte scintigraphy. AJR Am J Roentgenol 1991; 157: 527-31.

[86] Newman LG, Waller J, Palestro CJ, et al. Unsuspected osteomyelitis in diabetic foot ulcers. JAMA 1991; 266(9): 1246-51.

[87] Johnson JE, Kennedy EJ, Shereff MJ, Patel NC, Collier BD. Prospective study of bone, indium-111-labeled white blood cell, and gallium-67 scanning for the evaluation of osteomyelitis in the diabetic foot. Foot Ankle Int 1996; 17(1): 10-6.

[88] Harvey J, Cohen MM. Technetium-99-labeled leukocytes in diagnosing diabetic osteomyelitis in the foot. J Foot Ankle Surg 1997; 36: 209-14.

[89] Devillers A, Moisan A, Hennion F, Garin E, Poirier JY, Bourguet P. Contribution of technetium- $99 \mathrm{~m}$ hexamethylpropylene amine oxime labelled leucocyte scintigraphy to the diagnosis of diabetic foot infection. Eur J Nucl Med 1998; 25(2): 132-8.

[90] Palestro CJ, Caprioli R, Love C, et al. Rapid diagnosis of pedal osteomyelitis in diabetics with a technetium-99m-labeled monoclonal antigranulocyte antibody. J. Foot Ankle Surg 2003; 42: 2-8.

[91] Fosbøl M, Reving S, Petersen EH, Rossing P, Lajer M, Zerahn B. Three-phase bone scintigraphy for diagnosis of Charcot neuropathic osteoarthropathy in the diabetic foot - does quantitative data improve diagnostic value? Clin Physiol Funct Imaging 2015; 37(1): 30-36.

[92] Shagos GS, Shanmugasundaram P, Varma AK, Padma S, Sarma M. 18-F flourodeoxy glucose positron emission tomography-computed tomography imaging: A viable alternative to three phase bone scan in evaluating diabetic foot complications? Indian J Nucl Med 2015; 30: $97-103$. 
[93] Alazraki N, Dries D, Datz F, Lawrence P, Greenberg E, Taylor A. Value of a 24-hour image (four-phase bone scan) in assessing osteomyelitis in patients with peripheral vascular disease. J Nucl Med 1985; 26: 711-7.

[94] Israel O, Gips S, Jerushalmi J, Frenkel A, Front D. Osteomyelitis and soft-tissue infection: differential diagnosis with 24 hour/4 hour ratio of Tc-99m MDP uptake. Radiology 1987; 163: 725-6.

[95] Seldin DW, Heiken JP, Feldman F, Alderson PO. Effect of softtissue pathology on detection of pedal osteomyelitis in diabetics. $\mathrm{J}$ Nucl Med 1985; 26: 988-93.

[96] Schauwecker DS, Park HM, Burt RW, Mock BH, Wellman HN. Combined bone scintigraphy and indium-111 leukocyte scans in neuropathic foot disease. J Nucl Med 1988; 29: 1651-5.

[97] Blume PA, Dey HM, Daley LJ, Arrighi JA, Soufer R, Gorecki GA. Diagnosis of pedal osteomyelitis with Tc-99m HMPAO labeled leukocytes. J Foot Ankle Surg 1997; 36: 120-6; discussion 160.

[98] Poirier JY, Garin E, Derrien C, et al. Diagnosis of osteomyelitis in the diabetic foot with a $99 \mathrm{mTc}-\mathrm{HMPAO}$ leucocyte scintigraphy combined with a $99 \mathrm{mTc}-\mathrm{MDP}$ bone scintigraphy. Diabetes Metab 2002; 28: 485-90.

[99] Filippi L, Uccioli L, Giurato L, Schillaci O. Diabetic foot infection: usefulness of SPECT/CT for $99 \mathrm{mTc}-\mathrm{HMPAO}$-labeled leukocyte imaging. J Nucl Med 2009; 50: 1042-6.

[100] Vouillarmet J, Morelec I, Thivolet C. Assessing diabetic foot osteomyelitis remission with white blood cell SPECT/CT imaging. Diabet Med 2014; 31: 1093-9.

[101] Heiba S, Kolker D, Ong L, et al. Dual-isotope SPECT/CT impact on hospitalized patients with suspected diabetic foot infection: saving limbs, lives, and resources. Nucl Med Commun 2013; 34: 87784 .

[102] Ertugrul MB, Baktiroglu S, Salman S, et al. The diagnosis of osteomyelitis of the foot in diabetes: microbiological examination vs. magnetic resonance imaging and labelled leucocyte scanning. Diabet Med 2006; 23: 649-53.

[103] Knešaurek K, Kolker D, Vatti S, Heiba S. Precise fusion of MRI and dual energy $111 \mathrm{In} \mathrm{WBC} / 99 \mathrm{mTc}$ HDP SPECT/CT in the diabetic foot using companion CT: An example of SPECT/MRI imaging. Q. J Nucl Med Mol Imaging 2015; 59: 129-35.

[104] Dominguez-Gadea L, Martin-Curto LM, de la Calle H, Crespo A. Diabetic foot infections: scintigraphic evaluation with $99 \mathrm{Tcm}-$ labelled anti-granulocyte antibodies. Nucl Med Commun 1993; 14: 212-8.

[105] Capriotti G, Chianelli M, Signore A. Nuclear medicine imaging of diabetic foot infection: results of meta-analysis Nucl Med Commun 2006; 27: 757-64

[106] Oyen WJ, Netten PM, Lemmens JA, Claessens RA, Lutterman JA, van der Vliet JA, et al. Evaluation of infectious diabetic foot complications with indium-111-labeled human nonspecific immunoglobulin G. J Nucl Med 1992; 33: 1330-6.

[107] Delcourt A, Huglo D, Prangere T, et al. Comparison between Leukoscan (Sulesomab) and Gallium-67 for the diagnosis of osteomyelitis in the diabetic foot. Diabetes Metab 2005; 31: 125-33.

[108] Asli IN, Javadi H, Seddigh H, et al. The diagnostic value of (99m)Tc-IgG scintigraphy in the diabetic foot and comparison with (99m)Tc-MDP scintigraphy. J Nucl Med Technol 2011; 39: 226-30.

[109] Langer O, Mitterhauser M, Brunner M, et al. Synthesis of fluorine18-labeled ciprofloxacin for PET studies in humans Nucl Med Biol 2003; 30: 285-91.

[110] Dutta P, Bhansali A, Mittal BR, Singh B, Masoodi SR. Instant $99 \mathrm{mTc}$-ciprofloxacin scintigraphy for the diagnosis of osteomyelitis in the diabetic foot. Foot ankle Int 2006; 27: 716-22.

[111] Singh B, Sunil HV, Sharma S, et al. Efficacy of indigenously developed single vial kit preparation of $99 \mathrm{mTc}$-ciprofloxacin in the detection of bacterial infection: An Indian experience. Nucl Med Commun 2008; 29: 1123-9.

[112] Remedios D, Valabhji J, Oelbaum R, Sharp P, Mitchell R. 99mTcnanocolloid scintigraphy for assessing osteomyelitis in diabetic neuropathic feet. Clin. Radiol 1998; 53: 120-5.

[113] Aslangul E, M'bemba J, Caillat-Vigneron N, et al. Diagnosing diabetic foot osteomyelitis in patients without signs of soft tissue infection by coupling hybrid $67 \mathrm{Ga}$ SPECT/CT with bedside percutaneous bone puncture. Diabetes Care 2013; 36: 2203-10.
[114] Saeed S, Zafar J, Khan B, et al. Utility of 99mTc-labelled antimicrobial peptide ubiquicidin (29-41) in the diagnosis of diabetic foot infection. Eur J Nucl Med Mol Imaging 2013; 40: 737-43.

[115] Schwegler B, Stumpe KD, Weishaupt D, et al. Unsuspected osteomyelitis is frequent in persistent diabetic foot ulcer and better diagnosed by MRI than by $18 \mathrm{~F}-\mathrm{FDG}$ PET or $99 \mathrm{mTc}-\mathrm{MOAB}$. J Intern Med 2008; 263: 99-106.

[116] Nawaz A, Torigian DA, Siegelman ES, Basu S, Chryssikos T, Alavi A. Diagnostic performance of FDG-PET, MRI, and plain film radiography (PFR) for the diagnosis of osteomyelitis in the diabetic foot. Mol Imaging Biol 2010; 12: 335-42.

[117] Basu S, Chryssikos T, Houseni M, et al. Potential role of FDG PET in the setting of diabetic neuro-osteoarthropathy: can it differentiate uncomplicated Charcot's neuroarthropathy from osteomyelitis and soft-tissue infection? Nucl Med Commun 2007; 28(6): 465-72.

[118] Keidar Z, Militianu D, Melamed E, Bar-Shalom R, Israel O. The diabetic foot: initial experience with 18F-FDG PET/CT. J Nucl Med 2005; 46: 444-9.

[119] Kagna O, Srour S, Melamed E, Militianu D, Keidar Z. FDG $\mathrm{PET} / \mathrm{CT}$ imaging in the diagnosis of osteomyelitis in the diabetic foot. Eur J Nucl Med Mol Imaging 2012; 39: 1545-50.

[120] Familiari D, Glaudemans AW, Vitale V, et al. Can sequential 18FFDG PET/CT replace WBC imaging in the diabetic foot? J Nucl Med 2011; 52: 1012-9.

[121] Djekidel M, Brown RK, Piert M. Benefits of hybrid SPECT/CT for (111)In-oxine- and Tc-99m-hexamethylpropylene amine oximelabeled leukocyte imaging. Clin Nucl Med 2011; 36: e50-6.

[122] Kim HO, Na SJ, Oh SJ, et al. Usefulness of adding SPECT/CT to 99mTc-hexamethylpropylene amine oxime (HMPAO)-labeled leukocyte imaging for diagnosing prosthetic joint infections. J Comput Assist Tomogr 2014; 38: 313-9.

[123] Dumarey N, Egrise D, Blocklet D, et al. Imaging infection with 18F-FDG-labeled leukocyte PET/CT: initial experience in $21 \mathrm{pa}-$ tients. J Nucl Med 2006; 47: 625-32.

[124] Aksoy SY, Asa S, Ozhan M, et al. FDG and FDG-labelled leucocyte PET/CT in the imaging of prosthetic joint infection. Eur J Nucl Med Mol Imaging 2014; 41: 556-64.

[125] Pakos EE, Fotopoulos AD, Stafilas KS, et al. Use of (99m)Tcsulesomab for the diagnosis of prosthesis infection after total joint arthroplasty. J. Int. Med. Res 2007; 35: 474-81.

[126] Iyengar KP, Vinjamuri S. Role of $99 \mathrm{mTc}$ Sulesomab in the diagnosis of prosthetic joint infections. Nucl Med Commun 2005; 26: 48996.

[127] Rubello D, Rampin L, Banti E, et al. Diagnosis of infected total knee arthroplasty with anti-granulocyte scintigraphy: the importance of a dual-time acquisition protocol Nucl Med Commun 2008; 29: 331-5.

[128] Rubello D, Rampin L, Banti E, et al. Antigranulocyte scintigraphy in infected hip prosthesis: the diagnostic importance of delayed 2024-h imaging and semiquantitative analysis Nucl Med Commun 2008; 29: 994-8.

[129] Gratz S, Behr TM, Reize P, Pfestroff A, Kampen WU, Höffken H. (99m)Tc-Fab' fragments (sulesomab) for imaging septically loosened total knee arthroplasty J Int Med Res 2009; 37: 54-67.

[130] Gratz S, Reize P, Pfestroff A, Höffken H. Intact versus fragmented $99 \mathrm{mTc}-$ monoclonal antibody imaging of infection in patients with septically loosened total knee arthroplasty J Int Med Res 2012; 40: 1335-42.

[131] Sousa R, Massada M, Pereira A, Fontes F, Amorim I, Oliveira A. Diagnostic accuracy of combined $99 \mathrm{mTc}$-sulesomab and $99 \mathrm{mTc}$ nanocolloid bone marrow imaging in detecting prosthetic joint infection Nucl Med Commun 2011; 32: 834-9.

[132] Fuster D, Soriano A, Garcia S, et al. Usefulness of $99 \mathrm{mTc}$ ciprofloxacin scintigraphy in the diagnosis of prosthetic joint infections Nucl Med Commun 2011; 32: 44-51.

[133] Lorberboym M, Feldbrin Z, Hendel D, Blankenberg FG, Schachter $\mathrm{P}$. The use of $99 \mathrm{mTc}-$ recombinant human annexin $\mathrm{V}$ imaging for differential diagnosis of aseptic loosening and low-grade infection in hip and knee prostheses J Nucl Med 2009; 50: 534-7.

[134] Choe H, Inaba Y, Kobayashi N, et al. Use of $18 \mathrm{~F}$-fluoride PET to determine the appropriate tissue sampling region for improved sensitivity of tissue examinations in cases of suspected periprosthetic infection after total hip arthroplasty Acta Orthop 2011; 82: 427-32. 
[135] Wenter V, Müller JP, Albert NL, et al. The diagnostic value of [(18)F]FDG PET for the detection of chronic osteomyelitis and implant-associated infection Eur J Nucl Med Mol Imaging 2016; 43: 749-61.

[136] Mumme T, Reinartz P, Alfer J, Müller-Rath R, Buell U, Wirtz DC. Diagnostic values of positron emission tomography versus triplephase bone scan in hip arthroplasty loosening Arch Orthop Trauma Surg 2005; 125: 322-9.

[137] Pill SG, Parvizi J, Tang PH, et al. Comparison of fluorodeoxyglucose positron emission tomography and (111)indium-white blood cell imaging in the diagnosis of periprosthetic infection of the hip. J Arthroplasty 2006; 21: 91-7.

[138] Delank K-S, Schmidt M, Michael JW, Dietlein M, Schicha H, Eysel P. The implications of 18 F-FDG PET for the diagnosis of endoprosthetic loosening and infection in hip and knee arthroplasty: results from a prospective, blinded study. BMC Musculoskelet. Disord 2006; 7: 20.

[139] Chryssikos T, Parvizi J, Ghanem E, Newberg A, Zhuang H, Alavi A. FDG-PET imaging can diagnose periprosthetic infection of the hip Clin Orthop Relat Res 2008; 466: 1338-42.

[140] Gravius S, Gebhard M, Ackermann D, Büll U, Hermanns-Sachweh B, Mumme T. Analysis of 18F-FDG uptake pattern in PET for diagnosis of aseptic loosening versus prosthesis infection after total knee arthroplasty. A prospective pilot study. Nuklearmedizin 2010; 49: 115-23.

[141] Stumpe KD, Nötzli HP, Zanetti M, et al. FDG PET for differentiation of infection and aseptic loosening in total hip replacements: comparison with conventional radiography and three-phase bone scintigraphy Radiology 2004; 231: 333-41.

[142] Reinartz P, Mumme T, Hermanns B, et al. Radionuclide imaging of the painful hip arthroplasty: positron-emission tomography versus triple-phase bone scanning. J. Bone Joint Surg Br 2005; 87: 465-70.

[143] Chacko TK, Zhuang H, Stevenson K, Moussavian B, Alavi A. The importance of the location of fluorodeoxyglucose uptake in periprosthetic infection in painful hip prostheses Nucl Med Commun 2002; 23: 851-5.

[144] Love C, Marwin SE, Tomas MB, et al. Diagnosing infection in the failed joint replacement: A comparison of coincidence detection 18F-FDG and $111 \mathrm{In}$-labeled leukocyte/99mTc-sulfur colloid marrow imaging. J Nucl Med 2004; 45: 1864-71.

[145] Chen SH, Ho KC, Hsieh PH, Lee MS, Yen TC. Potential clinical role of $18 \mathrm{~F}$ FDG-PET/CT in detecting hip prosthesis infection: A study in patients undergoing two-stage revision arthroplasty with an interim spacer. Q. J Nucl Med Mol Imaging 2010; 54: 429-35.

[146] Stumpe KD, Romero J, Ziegler O, et al. The value of FDG-PET in patients with painful total knee arthroplasty Eur J Nucl Med Mol Imaging 2006; 33: 1218-25.

[147] von Schulthess GK, Meier N, Stumpe KD. Joint accumulations of FDG in whole body PET scans Nuklearmedizin 2001; 40: 193-7.

[148] Meyer M, Gast T, Raja S, Hubner K. Increased F-18 FDG accumulation in an acute fracture. Clin Nucl Med 1994; 19: 13-4.

[149] Manthey N, Reinhard P, Moog F, Knesewitsch P, Hahn K, Tatsch $\mathrm{K}$. The use of $\left[{ }^{18} \mathrm{~F}\right]$ fluorodeoxyglucose positron emission tomography to differentiate between synovitis, loosening and infection of hip and knee prostheses. Nucl Med Commun 2002; 23: 645-53.

[150] Liu Y. Orthopedic surgery-related benign uptake on FDG-PET: case examples and pitfalls Ann Nucl Med 2009; 23: 701-8.

[151] Henry G, Garner WL. Inflammatory mediators in wound healing Surg Clin North Am 2003; 83: 483-507.

[152] Zhuang H, Sam JW, Chacko TK, et al. Rapid normalization of osseous FDG uptake following traumatic or surgical fractures Eur J Nucl Med Mol Imaging 2003; 30: 1096-103.

[153] Kaim AH, Gross T, von Schulthess GK. Imaging of chronic posttraumatic osteomyelitis Eur Radiol 2002; 12: 1193-202.

[154] Piriou P, de Loynes B, Garreau de Loubresse C, Judet T. Use of combined gallium-technetium scintigraphy to determine the interval before second-stage prosthetic reimplantation in hip arthroplasty infection: A consecutive series of 30 cases. Rev Chir 2003; 89: 28796.

[155] Malamitsi J, Papadopoulos A, Vezyrgianni A, Dalianis K, Boutsikou M, Giamarellou $\mathrm{H}$. The value of successive Infecton scans in assessing the presence of chronic bone and joint infection and in predicting its evolution after treatment and after a prolonged follow-up Nucl Med Commun 2011; 32: 1060-9.

[156] Aryana K, Hootkani A, Sadeghi R, et al. (99m)Tc-labeled ubiquicidin scintigraphy: A promising method in hip prosthesis infection diagnosis. Nuklearmedizin 2012; 51: 133-9.

[157] Nazari B, Azizmohammadi Z, Rajaei M, et al. Role of 99mTcubiquicidin 29-41 scintigraphy to monitor antibiotic therapy in patients with orthopedic infection: A preliminary study. Nucl Med Commun 2011; 32: 745-51.

[158] Habib G, Lancellotti P, Antunes MJ, et al. ESC Guidelines for the management of infective endocarditis. Eur Heart J 2015; 36: ehv319.

[159] Hamburger M, Stein L. Streptococcus viridans subacute bacterial endocarditis; two week treatment schedule with penicillin. J Am Med Assoc 1952; 149: 542-5.

[160] Durack DT, Beeson PB. Experimental bacterial endocarditis. II. Survival of a bacteria in endocardial vegetations. Br J Exp Pathol 1972; 53: 50-3.

[161] Iung B, Erba PA, Petrosillo N, Lazzeri E. Common diagnostic flowcharts in infective endocarditis. Q. J Nucl Med Mol Imaging 2014; 58: 55-65.

[162] O'Brien K, Barnes D, Martin RH, Rae JR. Gallium-SPECT in the detection of prosthetic valve endocarditis and aortic ring abscess. J Nucl Med 1991; 32: 1791-3.

[163] Salem R, Boucher L, Laflamme L. Dual Tc-99m sestamibi and Gallium-67 SPECT localize a myocardial abscess around a bioprosthetic aortic valve Clin Nucl Med 2004; 29: 799-800.

[164] Thomson LE, Goodman MP, Naqvi TZ, et al. Aortic root infection in a prosthetic valve demonstrated by gallium-67 citrate SPECT Clin Nucl Med 2005; 30: 265-8.

[165] Wiseman J, Rouleau J, Rigo P, Strauss HW, Pitt B. Gallium-67 myocardial imaging for the detection of bacterial endocarditis. Radiology 1976; 120: 135-8.

[166] Melvin ET, Berger M, Lutzker LG, Goldberg E, Mildvan D. Noninvasive methods for detection of valve vegetations in infective endocarditis. Am J Cardiol 1981; 47: 271-8.

[167] Borst U, Becker W, Maisch B, Börner W, Kochsiek K. Indium-111 or Tc-99m-HMPAO marked granulocytes as specific markers of florid stage endocarditis--results comparing clinical, histological and scintigraphic findings in 30 patients with suspected endocarditis. Zeitschrift für Kardiol 1992; 81: 432-7.

[168] Cascini GL, De Palma D, Matteucci F, et al. Fever of unknown origin, infection of subcutaneous devices, brain abscesses and endocarditis Nucl Med Commun 2006; 27: 213-22.

[169] Erba PA, Conti U, Lazzeri E, et al. Added value of 99mTcHMPAO-labeled leukocyte SPECT/CT in the characterization and management of patients with infectious endocarditis. J Nucl Med 2012; 53: 1235-43.

[170] Litzler P-Y, Manrique A, Etienne M, et al. Leukocyte SPECT/CT for detecting infection of left-ventricular-assist devices: preliminary results. J Nucl Med 2010; 51: 1044-8.

[171] McWilliams ET, Yavari A, Raman V. Aortic root abscess: multimodality imaging with computed tomography and gallium-67 citrate single-photon emission computed tomography/computed tomography hybrid imaging. J Cardiovasc Comput Tomogr 2011; 5: 122-4.

[172] Moghadam-Kia S, Nawaz A, Millar BC, et al. Imaging with (18)FFDG-PET in infective endocarditis: promising role in difficult diagnosis and treatment monitoring. Hell. J Nucl Med 2009; 12: $165-$ 7.

[173] Van Riet J, Hill EE, Gheysens O, et al. (18)F-FDG PET/CT for early detection of embolism and metastatic infection in patients with infective endocarditis. Eur J Nucl Med Mol Imaging 2010; 37 : 1189-97.

[174] Özcan C, Asmar A, Gill S, Thomassen A, Diederichsen AC. The value of FDG-PET/CT in the diagnostic work-up of extra cardiac infectious manifestations in infectious endocarditis. Int $\mathrm{J}$ Cardiovasc Imaging 2013; 29: 1629-37.

[175] Bonfiglioli R, Nanni C, Morigi JJ, et al. ${ }^{18}$ F-FDG PET/CT diagnosis of unexpected extracardiac septic embolisms in patients with suspected cardiac endocarditis. Eur J Nucl Med Mol Imaging 2013; 40(8): 1190-6. 
[176] Saby L, Laas O, Habib G, et al. Positron emission tomography/computed tomography for diagnosis of prosthetic valve endocarditis: increased valvular 18F-fluorodeoxyglucose uptake as a novel major criterion. J Am Coll Cardiol 2013; 61: 2374-82.

[177] Kouijzer IJ, Vos FJ, Janssen MJ, van Dijk AP, Oyen WJ, BleekerRovers CP. The value of $18 \mathrm{~F}-\mathrm{FDG} \mathrm{PET} / \mathrm{CT}$ in diagnosing infectious endocarditis. Eur J Nucl Med Mol Imaging 2013; 40: 1102-7.

[178] Chen W, Kim J, Molchanova-Cook OP, Dilsizian V. The potential of FDG PET/CT for early diagnosis of cardiac device and prosthetic valve infection before morphologic damages ensue. Curr. Cardiol. Rep 2014; 16: 459 .

[179] Kestler M, Muñoz P, Rodríguez-Créixems M, et al. Group for the Management of Infectious Endocarditis (GAME). Role of (18)FFDG PET in Patients with Infectious Endocarditis. J Nucl Med 2014; 55(7): 1093-8.

[180] Orvin K, Goldberg E, Bernstine H, et al. The role of FDG-PET/CT imaging in early detection of extra-cardiac complications of infective endocarditis. Clin Microbiol Infect 2015; 21: 69-76.

[181] Ricciardi A, Sordillo P, Ceccarelli L, et al. 18-Fluoro-2deoxyglucose positron emission tomography-computed tomography: An additional tool in the diagnosis of prosthetic valve endocarditis. Int J Infect Dis 2014; 28: 219-24.

[182] Rouzet F, Chequer R, Benali K, et al. Respective performance of $18 F-F D G$ PET and radiolabeled leukocyte scintigraphy for the diagnosis of prosthetic valve endocarditis. J Nucl Med 2014; 55: 1980-5.

[183] Asmar A, Ozcan C, Diederichsen AC, Thomassen A, Gill S. Clinical impact of $18 \mathrm{~F}-\mathrm{FDG}-\mathrm{PET} / \mathrm{CT}$ in the extra cardiac work-up of patients with infective endocarditis. Eur Heart J Cardiovasc Imaging 2014; 15: 1013-9.

[184] Vaidyanathan S, Patel CN, Scarsbrook AF, Chowdhury FU. FDG $\mathrm{PET} / \mathrm{CT}$ in infection and inflammation--current and emerging clinical applications. Clin Radiol 2015; 70: 787-800.

[185] Erba PA, Sollini M, Boni R, Lazzeri E. Other imaging modalities in infective endocarditis diagnosis.infect endocarditis epidemiol Diagnosis, Imaging, Ther Prev 1st ed. 1st ed.2016; 51-80.[http: //dx.doi.org/10.1007/978-3-319-32432-6 6

[186] Shreve PD, Anzai Y, Wahl RL. Pitfalls in oncologic diagnosis with FDG PET imaging: physiologic and benign variants. Radiographics 1999; 19: 61-77-1.

[187] Sollini M, Boni R, Antunovic L, Kirienko M, Lazzeri E, Erba PA. The Role of Nuclear Cardiac Imaging in Infective Endocarditis. Curr. Cardiovasc. Imaging Rep. Curr Cardiovasc Imaging Rep 2017; 10: 22 .

[188] de Groot M, Meeuwis AP, Kok PJ, Corstens FH, Oyen WJ. Influence of blood glucose level, age and fasting period on nonpathological FDG uptake in heart and gut. Eur J Nucl Med Mol Imaging 2005; 32(1): 98-101.

[189] Lum D, Wandell S, Ko J, Coel M. Positron emission tomography of thoracic malignancies. Reduction of myocardial fluorodeoxyglucose uptake artifacts with a carbohydrate restricted diet. Clin Positron Imaging 2000; 3: 155

[190] Williams G, Kolodny GM. Suppression of myocardial 18F-FDG uptake by preparing patients with a high-fat, low-carbohydrate diet. AJR. Am J Roentgenol 2008; 190: W151-6.

[191] Persson E. Lipoprotein lipase, hepatic lipase and plasma lipolytic activity Effects of heparin and a low molecular weight heparin fragment (Fragmin) Acta Med Scand Suppl 1988; 724: 1-56.

[192] Minamimoto R, Morooka M, Kubota K, et al. Value of FDG$\mathrm{PET} / \mathrm{CT}$ using unfractionated heparin for managing primary cardiac lymphoma and several key findings. J Nucl Cardiol 2011; 18: 51620 .

[193] Dorbala S, Di Carli MF, Delbeke D, et al. SNMMI/ASNC/SCCT guideline for cardiac SPECT/CT and PET/CT 1.0. J Nucl Med 2013; 54(8): 1485-507.

[194] Fan C-M, Fischman AJ, Kwek BH, Abbara S, Aquino SL. Lipomatous hypertrophy of the interatrial septum: increased uptake on FDG PET AJR Am J Roentgenol 2005; 184: 339-42.

[195] Kobayashi Y, Ishii K, Oda K, Nariai T, Tanaka Y, Ishiwata K, et al. Aortic wall inflammation due to Takayasu arteritis imaged with 18F-FDG PET coregistered with enhanced CT. J Nucl Med 2005; 46: 917-22.
[196] Kaderli AA, Baran I, Aydin O, et al. Diffuse involvement of the heart and great vessels in primary cardiac lymphoma. Eur J Echocardiogr 2010; 11: 74-6.

[197] García JR, Simo M, Huguet M, Ysamat M, Lomeña F. Usefulness of 18-fluorodeoxyglucose positron emission tomography in the evaluation of tumor cardiac thrombus from renal cell carcinoma. Clin Transl Oncol 2006; 8: 124-8.

[198] Abidov A, D'agnolo A, Hayes SW, Berman DS, Waxman AD. Uptake of FDG in the area of a recently implanted bioprosthetic mitral valve Clin Nucl Med 2004; 29: 848.

[199] Schouten LR, Verberne HJ, Bouma BJ, van Eck-Smit BL, Mulder BJ. Surgical glue for repair of the aortic root as a possible explanation for increased F-18 FDG uptake. J Nucl Cardiol 2008; 15: 1467.

[200] Rouzet F, Chequer R, Benali K, et al. Respective performance of 18F-FDG PET and radiolabeled leukocyte scintigraphy for the diagnosis of prosthetic valve endocarditis. J Nucl Med 2014; 55(12): 1980-5.

[201] Pizzi MN, Roque A, Cuéllar-Calabria H, et al. 18F-FDG-PET/CTA of Prosthetic Cardiac Valves and Valve-Tube Grafts: Infective Versus Inflammatory Patterns. JACC Cardiovasc Imaging 2016; 9(10): 1224-7.

[202] Klug D, Balde M, Pavin D, et al. Risk factors related to infections of implanted pacemakers and cardioverter-defibrillators: results of a large prospective study Circulation 2007; 116: 1349-55.

[203] Margey R, McCann H, Blake G, et al. Contemporary management of and outcomes from cardiac device related infections Europace 2010; 12: 64-70.

[204] Klug D, Lacroix D, Savoye C, Goullard L, Grandmougin D, Hennequin JL, et al. Systemic infection related to endocarditis on pacemaker leads: clinical presentation and management Circulation 1997; 95: 2098-107.

[205] Chu VH, Crosslin DR, Friedman JY, et al. Staphylococcus aureus bacteremia in patients with prosthetic devices: costs and outcomes Am J Med 2005; 118: 1416.

[206] Cacoub P, Leprince P, Nataf P, et al. Pacemaker infective endocarditis Am J Cardiol 1998; 82: 480-4.

[207] Sandoe JA, Barlow G, Chambers JB, et al. Guidelines for the diagnosis, prevention and management of implantable cardiac electronic device infection Report of a joint Working Party project on behalf of the British Society for Antimicrobial Chemotherapy (BSAC, host organization), British Heart Rh J Antimicrob Chemother 2015; 70: 325-59.

[208] Mangram AJ, Horan TC, Pearson ML, Silver LC, Jarvis WR. Guideline for prevention of surgical site infection, 1999 Hospital Infection Control Practices Advisory Committee Infect Control Hosp Epidemiol 1999; 20: 250-78-80.

[209] Mond HG, Irwin M, Ector H, Proclemer A. The world survey of cardiac pacing and cardioverter-defibrillators: calendar year 2005 an International Cardiac Pacing and Electrophysiology Society (ICPES) project. Pacing Clin. Electrophysiol 2008; 31: 1202-12.

[210] Da Costa A, Kirkorian G, Chevalier P, et al. Infections secondary to implantation of cardiac pacemakers. Arch Mal Coeur Vaiss 1998; 91: 753-7.

[211] Klug D, Wallet F, Lacroix D, et al. Local symptoms at the site of pacemaker implantation indicate latent systemic infection Heart 2004; 90: 882-6.

[212] Uslan DZ, Dowsley TF, Sohail MR, et al. Cardiovascular implantable electronic device infection in patients with Staphylococcus aureus bacteremia. Pacing Clin Electrophysiol 2010; 33: 407-13.

[213] Murdoch DR, Corey GR, Hoen B, et al. Clinical presentation, etiology, and outcome of infective endocarditis in the 21 st century: The international collaboration on endocarditis-prospective cohort study. Arch Intern Med 2009; 169: 463-73.

[214] Vogt PR, Sagdic K, Lachat M, Candinas R, von Segesser LK, Turina MI. Surgical management of infected permanent transvenous pacemaker systems: ten year experience. J Card Surg 1996; 11: $180-6$.

[215] Darouiche RO. Treatment of infections associated with surgical implants. N Engl J Med 2004; 350: 1422-9.

[216] Sohail MR, Uslan DZ, Khan AH, et al. Management and outcome of permanent pacemaker and implantable cardioverter-defibrillator infections. J Am Coll Cardiol 2007; 49: 1851-9. 
[217] Wilkoff BL. How to treat and identify device infections. Heart Rhythm 2007; 4: 1467-70.

[218] Uslan DZ, Sohail MR, St Sauver JL, et al. Permanent pacemaker and implantable cardioverter defibrillator infection: A populationbased study. Arch Intern Med 2007; 167: 669-75.

[219] Johansen JB, Jørgensen OD, Møller M, Arnsbo P, Mortensen PT, Nielsen JC. Infection after pacemaker implantation: infection rates and risk factors associated with infection in a population-based cohort study of 46299 consecutive patients. Eur Heart J 2011; 32: 991-8.

[220] Goodman LR, Almassi GH, Troup PJ, et al. Complications of automatic implantable cardioverter defibrillators: radiographic, CT, and echocardiographic evaluation. Radiology. 1989; 170: 447-52.

[221] Kelly PA, Wallace S, Tucker B, et al. Postoperative infection with the automatic implantable cardioverter defibrillator: clinical presentation and use of the gallium scan in diagnosis. Pacing Clin Electrophysiol 1988; 11: 1220-5.

[222] Matsushita K, Tsuboi N, Nanasato M, et al. Intravenous vegetation of methicillin-resistant Staphylococcus aureus induced by central venous catheter in a patient with implantable cardioverterdefibrillator: A case report. J Cardiol 2002; 40: 31-5.

[223] Bhadelia RA, Oates E. Early cardioverter defibrillator infection: value of indium-111 leukocyte imaging. Ann Thorac Surg 1997; 63: 236-8.

[224] Erba PA, Sollini M, Conti U, et al. Radiolabeled WBC scintigraphy in the diagnostic workup of patients with suspected device-related infections. JACC Cardiovase Imaging 2013; 6(10): 1075-86.

[225] Almirante B, Miró JM. Infections associated with prosthetic heart valves, vascular prostheses, and cardiac pacemakers and defibrillators. Enfermedades Infecc. Microbiol Clín 2008; 26: 647-64.

[226] Roman CD, Habibian MR, Martin WH. Identification of an infected left ventricular assist device after cardiac transplant by indium-111 WBC scintigraphy. Clin Nucl Med 2005; 30: 16-7.

[227] Schiavo R, Ricci A, Pontillo D, Bernardini G, Melacrinis FF, Maccafeo S. Implantable cardioverter-defibrillator lead infection detected by $99 \mathrm{mTc}$-sulesomab single-photon emission computed tomography/computed tomography 'fusion' imaging. J Cardiovasc Med 2009; 10: 883-4.

[228] Ploux S, Riviere A, Amraoui S, et al. Positron emission tomography in patients with suspected pacing system infections may play a critical role in difficult cases. Heart Rhythm 2011; 8: 1478-81.

[229] Cautela J, Alessandrini S, Cammilleri S, et al. Diagnostic yield of FDG positron-emission tomography/computed tomography in patients with CEID infection: A pilot study. Europace 2013; 15(2): 252-7.

[230] Vos FJ, Bleeker-Rovers CP, Sturm PD, et al. 18F-FDG PET/CT for detection of metastatic infection in gram-positive bacteremia. $\mathrm{J}$ Nucl Med 2010; 51: 1234-40.

[231] Abikhzer G, Turpin S, Bigras J-L. Infected pacemaker causing septic lung emboli detected on FDG PET/CT. J Nucl Cardiol 2010; 17: 514-5.

[232] Costo S, Hourna E, Massetti M, Belin A, Bouvard G, Agostini D. Impact of F-18 FDG PET-CT for the diagnosis and management of infection in JARVIK 2000 device. Clin Nucl Med 2011; 36: e18891.

[233] Bensimhon L, Lavergne T, Hugonnet F, et al. Whole body [(18) F]fluorodeoxyglucose positron emission tomography imaging for the diagnosis of pacemaker or implantable cardioverter defibrillator infection: A preliminary prospective study. Clin Microbiol Infect 2011; 17: 836-44.

[234] Sarrazin JF, Philippon F, Tessier M, et al. Usefulness of fluorine-18 positron emission tomography/computed tomography for identification of cardiovascular implantable electronic device infections. J Am Coll Cardiol 2012; 59: 1616-25.

[235] Leccisotti L, Perna F, Lago M, et al. Cardiovascular implantable electronic device infection: delayed vs standard FDG PET-CT imaging. J Nucl Cardiol 2014; 21: 622-32.

[236] Homer-Vanniasinkam S. Surgical site and vascular infections: treatment and prophylaxis. Int J Infect Dis 2007; 11 Suppl 1: S1722.

[237] Annovazzi A, Bagni B, Burroni L, D’Alessandria C, Signore A. Nuclear medicine imaging of inflammatory/infective disorders of the abdomen. Nucl Med Commun 2005; 26: 657-64.
[238] Lou L, Alibhai KN, Winkelaar GB, Turnbull RG, et al. 99mTcWBC scintigraphy with SPECT/CT in the evaluation of arterial graft infection. Nucl Med Commun 2010; 31: 411-6.

[239] Erba PA, Leo G, Sollini M, et al. Radiolabelled leucocyte scintigraphy versus conventional radiological imaging for the management of late, low-grade vascular prosthesis infections. Eur J Nucl Med Mol Imaging 2014; 41(2): 357-68.

[240] Liberatore M, Misuraca M, Calandri E, et al. White blood cell scintigraphy in the diagnosis of infection of endovascular prostheses within the first month after implantation. Med Sci Monit 2006; 12: MT5-9

[241] Shahidi S, Eskil A, Lundof E, Klaerke A, Jensen BS. Detection of abdominal aortic graft infection: comparison of magnetic resonance imaging and indium-labeled white blood cell scanning. Ann Vasc Surg 2007; 21: 586-92.

[242] FitzGerald SF, Kelly C, Humphreys H. Diagnosis and treatment of prosthetic aortic graft infections: confusion and inconsistency in the absence of evidence or consensus. J Antimicrob Chemother 2005; 56: 996-9.

[243] Tronco GG, Love C, Rini JN, et al. Diagnosing prosthetic vascular graft infection with the antigranulocyte antibody $99 \mathrm{mTc}-$ fanolesomab. Nucl Med Commun 2007; 28: 297-300.

[244] Bachleda P, Kalinová L, Váchalová M, Koranda P. Unused arteriovenous grafts as a source of chronic infection in haemodialysed patients with relevance to diagnosis of Fluorodeoxyglucose PET/CT examination. Ann Acad Med Singapore 2012; 41(8): 3358.

[245] Burroni L, D’Alessandria C, Signore A. Diagnosis of vascular prosthesis infection: PET or SPECT? J Nucl Med 2007; 48: 1227-9.

[246] Fukuchi K, Ishida Y, Higashi M, et al. Detection of aortic graft infection by fluorodeoxyglucose positron emission tomography: comparison with computed tomographic findings. J Vasc Surg 2005; 42: 919-25.

[247] Keidar Z, Nitecki S. FDG-PET for the detection of infected vascular grafts. Q. J Nucl Med Mol 2009; 53: 35-40.

[248] Keidar Z, Pirmisashvili N, Leiderman M, Nitecki S, Israel O. 18FFDG uptake in noninfected prosthetic vascular grafts: incidence, patterns, and changes over time. J Nucl Med 2014; 55: 392-5.

[249] Bruggink JLM, Glaudemans AWJM, Saleem BR, Meerwaldt R, Alkefaji H, Prins TR, et al. Accuracy of FDG-PETeCT in the diagnostic work-up of vascular prosthetic graft infection. Eur J. Vasc. Endovasc. Surg Elsevier Ltd; 2010; 40: 348-54.

[250] Chang CY, Chang CP, Shih CC, et al. Added value of dual-timepoint 18F-FDG PET/CT with delayed imaging for detecting aortic graft infection: An observational study. Medicine (Baltimore) 2015; 94: e1124.

[251] Wassélius J, Malmstedt J, Kalin B, et al. High 18F-FDG Uptake in synthetic aortic vascular grafts on PET/CT in symptomatic and asymptomatic patients. J Nucl Med 2008; 49(10): 1601-5.

[252] Berger P, Vaartjes I, Scholtens A, et al. Differential FDG-PET uptake patterns in uninfected and infected central prosthetic vascular grafts. Eur J Vasc Endovasc Surg 2015; 50: 376-83.

[253] Saleem BR, Berger P, Vaartjes I, et al. Modest utility of quantitative measures in (18)F-fluorodeoxyglucose positron emission tomography scanning for the diagnosis of aortic prosthetic graft infection. J Vasc Surg 2015; 61: 965-71.

[254] Sah B-R, Husmann L, Mayer D, et al. Diagnostic performance of 18F-FDG-PET/CT in vascular graft infections. Eur J Vasc Endovasc Surg 2015; 49: 455-64.

[255] Spacek M, Belohlavek O, Votrubova J, Sebesta P, Stadler P. Diagnostics of "non-acute" vascular prosthesis infection using $18 \mathrm{~F}-\mathrm{FDG}$ PET/CT: our experience with 96 prostheses. Eur J Nucl Med Mol Imaging 2009; 36(5): 850-8.

[256] Husmann L, Sah B-R, Scherrer A, Burger IA, Stolzmann P, Weber $\mathrm{R}$, et al. 18F-FDG PET/CT for therapy control in vascular graft infections: A first feasibility study. J Nucl Med 2015; 56: 1024-9.

[257] Knochel JQ, Koehler PR, Lee TG, Welch DM. Diagnosis of abdominal abscesses with computed tomography, ultrasound, and 111 In leukocyte scans. Radiology 1980; 137: 425-32.

[258] Lin C-M, Hung G-U, Chao T-H, Lin W-Y, Wang S-J. The limited use of ultrasound in the detection of abdominal abscesses in patients after colorectal surgery: compared with gallium scan and computed tomography. Hepatogastroenterology 2005; 52: 79-81. 
[259] Tsai SC, Chao TH, Lin WY, Wang SJ. Abdominal abscesses in patients having surgery: An application of Ga-67 scintigraphic and computed tomographic scanning Clin Nucl Med 2001; 26: 761-4.

[260] Liberatore M, Calandri E, Ciccariello G, et al. The labeledleukocyte scan in the study of abdominal abscesses Mol Imaging Biol 2010; 12: 563-9.

[261] Lantto E. Investigation of suspected intra-abdominal sepsis: the contribution of nuclear medicine Scand J Gastroenterol Suppl 1994; 203: 11-4.

[262] Datz FL, Luers P, Baker WJ, Christian PE. Improved detection of upper abdominal abscesses by combination of $99 \mathrm{mTc}$ sulfur colloid and 111 In leukocyte scanning. AJR. Am J Roentgenol 1985; 144: 319-23.

[263] Seabold JE, Wilson DG, Lieberman LM, Boyd CM. Unsuspected extra-abdominal sites of infection: scintigraphic detection with indium-111-labeled leukocytes Radiology 1984 [cited 2016 Mar 29]; 151:213-7.
[264] Baba AA, McKillop JH, Cuthbert GF, Neilson W, Gray HW, Anderson JR. Indium 111 leucocyte scintigraphy in abdominal sepsis Do the results affect management? Eur J Nucl Med 1990; 16: 307-9

[265] Artiko V, Petrović M, Sobić-Saranović D, et al. Detection of gastrointestinal and abdominal infections by $99 \mathrm{mTc}$-antigranulocyte antibodies. Hepatogastroenterology 2009; 56: 1053-8.

[266] Jouret F, Lhommel R, Beguin C, et al. Positron-emission computed tomography in cyst infection diagnosis in patients with autosomal dominant polycystic kidney disease Clin J Am Soc Nephrol 2011; 6: $1644-50$

[267] Guettrot-Imbert G, Haroche J, Grimon G, et al. F-18 FDG-PET/CT in aseptic abscesses with recurrent febrile abdominal pain. Scand J Gastroenterol 2011; 46: 577-82.

[268] Love C, Tronco GG, Palestro CJ. Imaging of infection and inflammation with 99mTc-Fanolesomab. Q. J Nucl Med Mol Imaging 2006; 50: 113-20.

[269] Reavey HE, Alazraki AL, Simoneaux SF. Normal patterns of 18FFDG appendiceal uptake in children. Pediatr Radiol 2014; 44: 398 402. 